\title{
Pressure and temperature effects on formation of aminoacrylate intermediates of tyrosine phenol-lyase demonstrate reaction dynamics
}

DOI:

10.1021/acscatal.9b03967

\section{Document Version}

Accepted author manuscript

Link to publication record in Manchester Research Explorer

Citation for published version (APA):

Phillips, R. S., Craig, S., Kovalevsky, A. Y., Gerlits, O. O., Weiss, K. L., lorgu, A. I., Heyes, D. J., \& Hay, S. (2020). Pressure and temperature effects on formation of aminoacrylate intermediates of tyrosine phenol-lyase demonstrate reaction dynamics. ACS Catalysis. https://doi.org/10.1021/acscatal.9b03967

\section{Published in:}

ACS Catalysis

\section{Citing this paper}

Please note that where the full-text provided on Manchester Research Explorer is the Author Accepted Manuscript or Proof version this may differ from the final Published version. If citing, it is advised that you check and use the publisher's definitive version.

\section{General rights}

Copyright and moral rights for the publications made accessible in the Research Explorer are retained by the authors and/or other copyright owners and it is a condition of accessing publications that users recognise and abide by the legal requirements associated with these rights.

\section{Takedown policy}

If you believe that this document breaches copyright please refer to the University of Manchester's Takedown Procedures [http://man.ac.uk/04Y6Bo] or contact uml.scholarlycommunications@manchester.ac.uk providing relevant details, so we can investigate your claim.

\section{OPEN ACCESS}




\section{Pressure and Temperature Effects on Formation of Aminoacrylate Intermediates of Tyrosine Phenol-lyase Demonstrate Reaction Dynamics}

Robert S. Phillips* ${ }^{*}$, Steven Craig ${ }^{\ddagger}$, Andrey Kovalevsky Iorgu $^{\S}$, Derren J. Heyes ${ }^{\S}$, and Sam Hay ${ }^{\S}$

'Department of Chemistry, University of Georgia, Athens, GA 30602 USA

Department of Biochemistry and Molecular Biology, University of Georgia, Athens, GA 30602 USA

Neutron Scattering Division, Oak Ridge National Laboratory, Oak Ridge, TN 37831-6475

'Tennessee Wesleyan University, Athens, TN 37303

${ }^{\S}$ Manchester Institute of Biotechnology and Department of Chemistry, The University of Manchester, Manchester M17DN UK

*To whom correspondence should be addressed at Department of Chemistry, University of Georgia, Athens GA 30602 e-mail: plp@uga.edu 


\begin{abstract}
The structures of aminoacrylate intermediates of wild-type, F448A mutant, and perdeuterated tyrosine phenol-lyase (TPL) formed from L-tyrosine, 3-F-L-tyrosine, S-ethyl-L-cysteine, and L-serine, with 4-hydroxpyridine bound, were determined by X-ray crystallography. All the aminoacrylate Schiff's base structures in chain A are identical regardless of the substrate used to form them. The 4-hydroxypyridine is also in an identical location, except for F448A TPL, where it is displaced about $1 \AA$ due to the increased size of the active site. In chain B, we have found different complexes depending on the substrate. With wild-type TPL, L-tyrosine gave no density, 3-F-L-tyrosine gave a gem-diamine, and L-serine gave a gem-diamine, in chain B. S-Ethyl-L-cysteine formed an aminoacrylate in chain B with both wild-type and F448A TPL, but perdeuterated TPL with S-ethyl-Lcysteine formed a gem-diamine of aminoacrylate. The kinetics of aminoacrylate intermediate formation from L-tyrosine and S-ethyl-L-cysteine were followed by stopped-flow spectrophotometry at temperatures from 281 to $320 \mathrm{~K}$, and hydrostatic pressures ranging from 1 bar to $1.5 \mathrm{kbar}$ at $293 \mathrm{~K}$. There are large negative values of $\Delta S^{\ddagger}, \Delta C_{\mathrm{p}}, \Delta V^{\star}$, and $\Delta \beta^{\star}$ for aminoacrylate intermediate formation for L-tyrosine, but not for S-ethyl-L-cysteine. Formation of the aminoacrylate intermediates from Ltyrosine and S-ethyl-L-cysteine show heavy enzyme deuterium kinetic isotope effects with perdeuterated TPL that are strongly temperature and pressure dependent, and may be normal or inverse depending on conditions. These results suggest that conformational dynamics as well as vibrational coupling play a key role in the mechanism of the elimination reaction of L-tyrosine catalyzed by TPL.
\end{abstract}

Keywords: Enzyme mechanism; Pyridoxal-5'-phosphate; Stopped-flow kinetics; Temperature dependence; Pressure dependence; Heat capacity; Compressibility 
Tyrosine phenol-lyase (TPL, [EC 4.1.99.2]) is a pyridoxal-5'-phosphate (PLP) dependent enzyme that catalyzes the reversible elimination of L-tyrosine to form phenol and ammonium pyruvate (Eqn. 1) ${ }^{1}$. In addition to L-tyrosine, other amino acids with good leaving groups on the $\beta$-carbon, such as S-alkyl and S-aryl-L-cysteines (Eqn. 2 and 3), L-serine and O-alkyl-L-serines, and $\beta$-Cl-L-alanine, are substrates ${ }^{2-4}$; however, in contrast to the reaction of L-tyrosine, these reactions are not readily reversible. The mechanism of TPL has been of considerable interest, since phenol is formally not a<smiles></smiles><smiles>CCSC[C@H](N)C(=O)O</smiles><smiles>CC(=O)C(=O)[O-]</smiles>

good leaving group. Initially, the proposed mechanisms utilized general acid/base catalysis to activate the ring and facilitate elimination ${ }^{3-7}$. However, crystal structures of quinonoid complexes (see Scheme 1) showed that a bound substrate, 3 -fluoro-L-tyrosine, has a strained aromatic ring geometry ${ }^{8}$. Hence, we proposed that ground state strain contributes to TPL catalysis with L-tyrosine ${ }^{8}$. Mutagenesis of Phe-448 or Phe-449, proposed to be responsible for the substrate strain due to steric effects, to alanine results in $\sim 10^{4}$ fold decrease in activity, consistent with the proposed strain mechanism ${ }^{9}$. The X-ray crystal structures of F448A TPL complexes with L-alanine, L-methionine, L-phenylalanine, and 3fluoro-L-tyrosine are very similar to those of wild-type TPL ${ }^{10,11}$. 
A key intermediate in the mechanism of TPL is the $\alpha$-aminoacrylate Schiff's base, formed after the elimination of the $\beta$-leaving group (Scheme 1). Previous studies showed that aminoacrylate complexes of TPL can be kinetically trapped by binding of 4-hydroxypyridine (4-PD), an isoelectronic but non-nucleophilic analogue of the product, phenol ${ }^{12}$. We have now obtained crystal structures of wild-type TPL aminoacrylate intermediates formed from L-tyrosine, 3-fluoro-L-tyrosine, S-ethyl-Lcysteine, and L-serine, and of perdeuterated and F448A TPL aminoacrylate intermediates formed from S-ethyl-L-cysteine, with 4-PD bound. Furthermore, we have studied the effects of enzyme perdeuteration, temperature, and hydrostatic pressure on the kinetics of formation of aminoacrylate complexes by wild-type and F448A TPL with stopped-flow spectrophotometry. We observe significant 'heavy enzyme' kinetic isotope effects (KIEs) on both reactions, with the reactions displaying very different KIE behavior. These results are consistent with the ground state strain mechanism proposed previously $^{8,9}$, and, moreover, suggest that in the reaction of L-tyrosine, but not S-ethyl-L-cysteine, the elimination is coupled with protein conformational changes/dynamics, thus showing a link between substrate strain and conformational dynamics. 

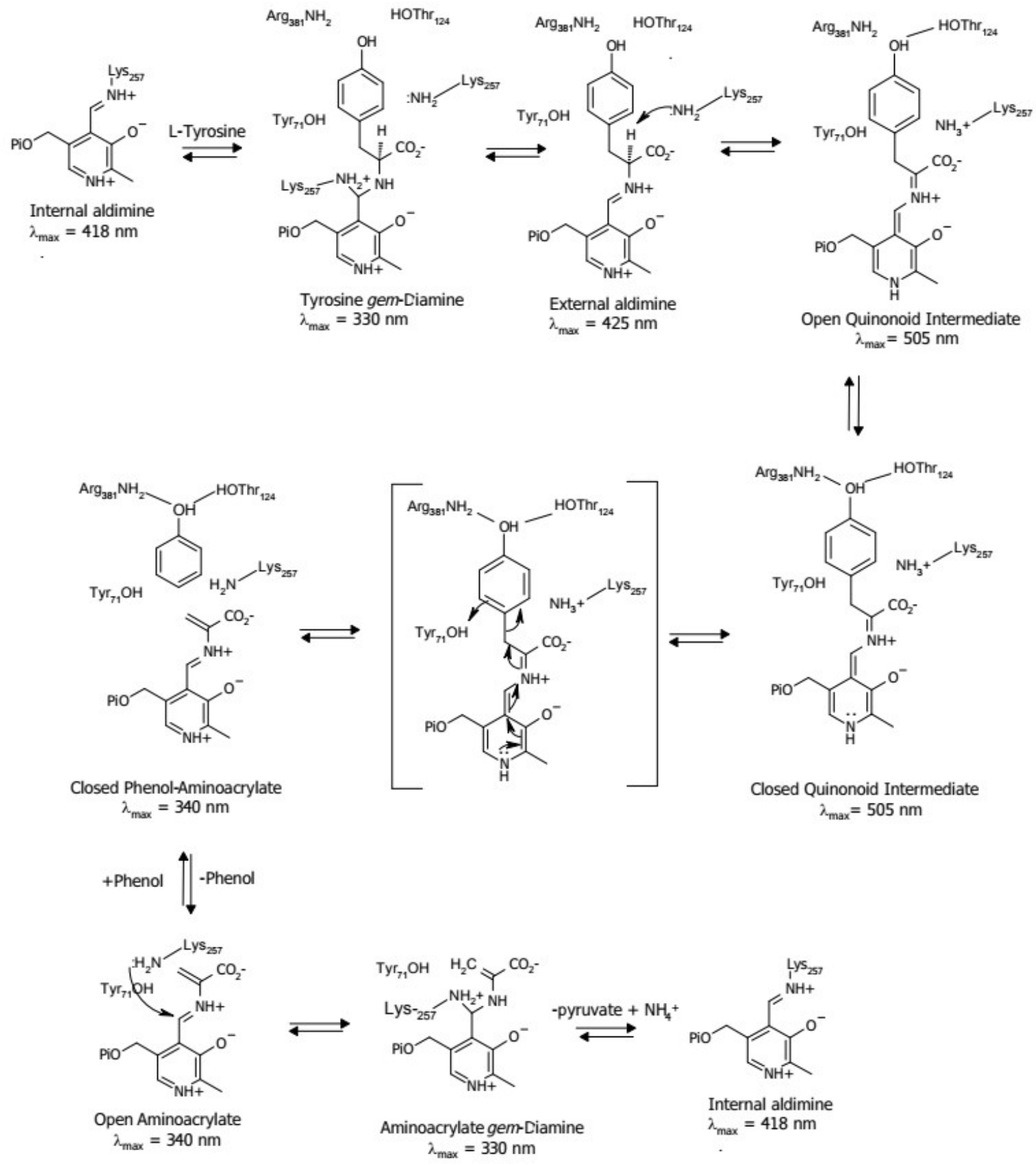

\section{Scheme 1. Proposed mechanism of tyrosine phenol-lyase}




\section{MATERIALS AND METHODS.}

Enzymes. Wild-type and F448A TPL were expressed and purified as previously described ${ }^{5}, 9$. Perdeuterated TPL was prepared by growing the cells expressing TPL in $\mathrm{D}_{2} \mathrm{O}$ in a minimal medium, with nondeuterated glycerol as a carbon source, at Oak Ridge National Laboratory. The perdeuterated protein was purified in $\mathrm{H}_{2} \mathrm{O}$ buffers, so exchangeable protons are largely expected to be non-deuterated. The perdeuterated TPL has an apparent molecular mass of $53,980 \mathrm{Da}$ in electrospray mass spectrometry (Figure S1), compared to the predicted mass of 51,500 Da from the protein sequence, for an increased mass of 2,480 $\mathrm{Da}$, or $4.8 \%$. There are 3,571 hydrogens based on the sequence, of which 766 are possibly exchangeable (on $\mathrm{N}$, O, or S). Since there are 2,805 predicted nonexchangeable hydrogens in the structure, the perdeuterated enzyme is $(2,480 / 2,805) \times 100 \%=88.4 \%$ deuterated.

Crystals. Crystals were grown in hanging drops in $0.05 \mathrm{M}$ triethanolamine-HCl, $\mathrm{pH} 8,1 \mathrm{mM}$ EDTA, 5 mM 2-mercaptoethanol, 0.5 mM PLP with 36-40\% PEG 5000 MME at ambient temperature, about 20$22^{\circ} \mathrm{C}^{10,11}$. Crystals appeared as yellow prisms in about 2 weeks. The complexes were prepared by soaking the crystals for 1-2 minutes in a cryoprotectant solution of the buffer, containing $40 \%$ PEG $5000 \mathrm{MME}$ and 20\% (v/v) ethylene glycol:dimethyl sulfoxide:glycerol (1:1:1) mixture, with either 4 mM L-tyrosine, 40 mM S-ethyl-L-cysteine, or 200 mM L-serine, and $10 \mathrm{mM}$ 4-PD, then flash cooling in liquid $\mathrm{N}_{2}$.

X-ray data collection and analysis. Diffraction data were collected at the SER-CAT ID-22 or BM-22 beamlines at Argonne National Laboratory at $100 \mathrm{~K}$ for $360^{\circ}$ with $0.5^{\circ}$ or $1.0^{\circ}$ oscillations. The data were integrated with $\mathrm{XDS}^{13}$ and scaled and merged with XSCALE. Resolution limits were determined by $\mathrm{CC}(1 / 2) \sim 0.3^{14}$. Phasing was performed by molecular replacement with PHASER ${ }^{15}$ using 2VLF.pdb as the search model. Model building was performed, and water and ligands were added, with COOT $^{16}$. The disorder in chain A was modeled by combining the structure of residues $18-43$, 346-376, and 428-456 from the small domain of 2TPL.pdb for the open conformation, and the same residues of 2VLF.pdb for the closed conformation. The open conformation was assigned to ALT.LOC 
A, while the closed conformation was assigned to ALT.LOC B. Occupancies for both conformations before refinement were set to 0.5. The structure of 4-pyridone (4PD) was built with CHEM3D (Cambridge Biosoft) and converted to cif format with PHENIX.ELBOW. The structure of the aminoacrylate complex was modeled with 0JO.cif. The models were refined with PHENIX.REFINE ${ }^{17}$ using TLS assignments by PHENIX.find_tls_groups. The statistics for the final structures are summarized in Table S1. The structure figures were prepared with PYMOL 2.1.0 (Schrodinger, LLC) and Ligplot $+{ }^{18}$.

Stopped-flow kinetics. The TPL was incubated with excess PLP for 30 minutes at room temperature, then rapidly passed through a gel-filtration column (PD-10, GE Healthcare), prior to performing the reactions. The reactions were performed in either $0.1 \mathrm{M}$ triethanolamine- $\mathrm{HCl}, \mathrm{pH} 8,0.1 \mathrm{M} \mathrm{KCl}$, or $0.05 \mathrm{M}$ potassium phosphate, $\mathrm{pH}$ 8.0, in an OLIS RSM-1000 rapid-scanning stopped-flow spectrophotometer for scanning experiments, or an Applied Photophysics SX-20 instrument for single wavelength experiments. The Applied Photophysics instrument was connected to a refrigerated water bath for temperature control. The scans were collected from 240-800 nm in 256 data points at $1000 \mathrm{~Hz}$ and data were analyzed with the Global Fit program ${ }^{19}$ provided by OLIS. Single wavelength kinetic data contained 1000 data points collected at 410 or $505 \mathrm{~nm}$ with a $4.5 \mathrm{~nm}$ bandpass, over 0.5-5 seconds, and were fit to either two or three exponentials with SciDAVis ${ }^{20}$. The temperatures used were between $8^{\circ}$ and $45^{\circ} \mathrm{C}$, and the enzyme was only at the highest temperature for about 5 minutes. No evidence of turbidity due to denaturation was seen at the highest temperature. At least three determinations at each condition were fit and the rate constants were averaged. The linear temperature dependence data were fit to the Eyring equation (Eqn. $4,{ }^{21}$ ) and the nonlinear temperature dependence data were fit to Eqn. 5 ${ }^{21}$ with SciDAVis ${ }^{20}$, with the reference temperature, $\mathrm{T}_{0}$, defined as $298.1 \mathrm{~K}$.

$$
\begin{array}{r}
\ln (k)=\ln \left(\mathrm{k}_{\mathrm{B}} \mathrm{T} / \mathrm{h}\right)-\Delta H^{\ddagger} / \mathrm{RT}+\Delta S^{\ddagger} / \mathrm{R} \\
\ln (k)=\ln \left(\mathrm{k}_{\mathrm{B}} \mathrm{T} / \mathrm{h}\right)-\left[\Delta H^{*}+\Delta C_{\mathrm{p}} *\left(\mathrm{~T}-\mathrm{T}_{0}\right)\right] / \mathrm{RT}+\left[\Delta S^{\ddagger}+\Delta C_{\mathrm{p}} * * \ln \left(\mathrm{T} / \mathrm{T}_{0}\right)\right] / \mathrm{R}
\end{array}
$$


High pressure stopped-flow data were collected in single wavelength mode on an HPSF-56 instrument from TgK Scientific (Bradford on Avon, UK). The reactions were performed at $20^{\circ} \mathrm{C}$ $(293.1 \mathrm{~K})$ in $0.1 \mathrm{M}$ triethanolamine- $\mathrm{HCl}, \mathrm{pH} 8,0.1 \mathrm{M} \mathrm{KCl}$. With L-tyrosine, the reactions were followed at $410 \mathrm{~nm}$, and with S-ethyl-L-cysteine, the reactions were followed at $505 \mathrm{~nm}$. The data were collected at 50,250,500,750,1000,1250, and 1500 bar and fit to two or three exponentials using the software provided by TgK Scientific. Transients were fitted to a 2 or 3-exponential function using the software from TgK Scientific in order to extract observed rate constants. The pressure dependence of these data was then fitted to Eqn. $6^{22}$ with SciDAVis ${ }^{20}$ in order to determine the apparent activation volume $\left(\Delta V^{\sharp}\right)$ and compressibility $\left(\Delta \beta^{\ddagger}\right)$ associated with each kinetic phase.

$$
k=k_{\mathrm{o}} \exp \left[\left(-\mathrm{P} \Delta V^{\ddagger} / \mathrm{RT}\right) \Delta \beta^{\ddagger} \mathrm{P}^{2} / 2 \mathrm{RT}\right]
$$

\section{RESULTS}

Structure of the aminoacrylate complexes of wild-type TPL. We showed previously that 4-PD, an isoelectronic and structural analogue of the product, phenol, binds to the aminoacrylate intermediate of TPL, stabilizing it and allowing for the kinetics of its formation to be determined spectroscopically ${ }^{12}$. The aminoacrylate complex has a unique absorption spectrum among PLP reaction intermediates, with a $\lambda_{\max }$ at about $350 \mathrm{~nm}$ and/or $460 \mathrm{~nm}$, the exact position depending on the enzyme ${ }^{12,23}$. Wild-type TPL crystals soaked with $4 \mathrm{mM}$ L-tyrosine and $10 \mathrm{mM}$ 4-PD show new electron density in the active site of chain A, which fits well to an aminoacrylate Schiff's base complex of PLP and 4-PD (Figure 1A, Figure S2); Note that TPL is a homotetramer, with the asymmetric unit a homodimer, and active sites found in chains A and B). However, there is the initial internal aldimine electron density evident in the active site of chain B (Figure S3). Two different TPL crystals soaked with L-tyrosine and 4-PD both showed new density of an aminoacrylate complex in chain A, and no new density in the active site of chain B. The aminoacrylate group in the complex in chain A is twisted slightly out of plane with the pyridine ring of the PLP (Figure 1A). The torsion angle of C3-C4-C4'-N is $-15^{\circ}$. There is no 
A

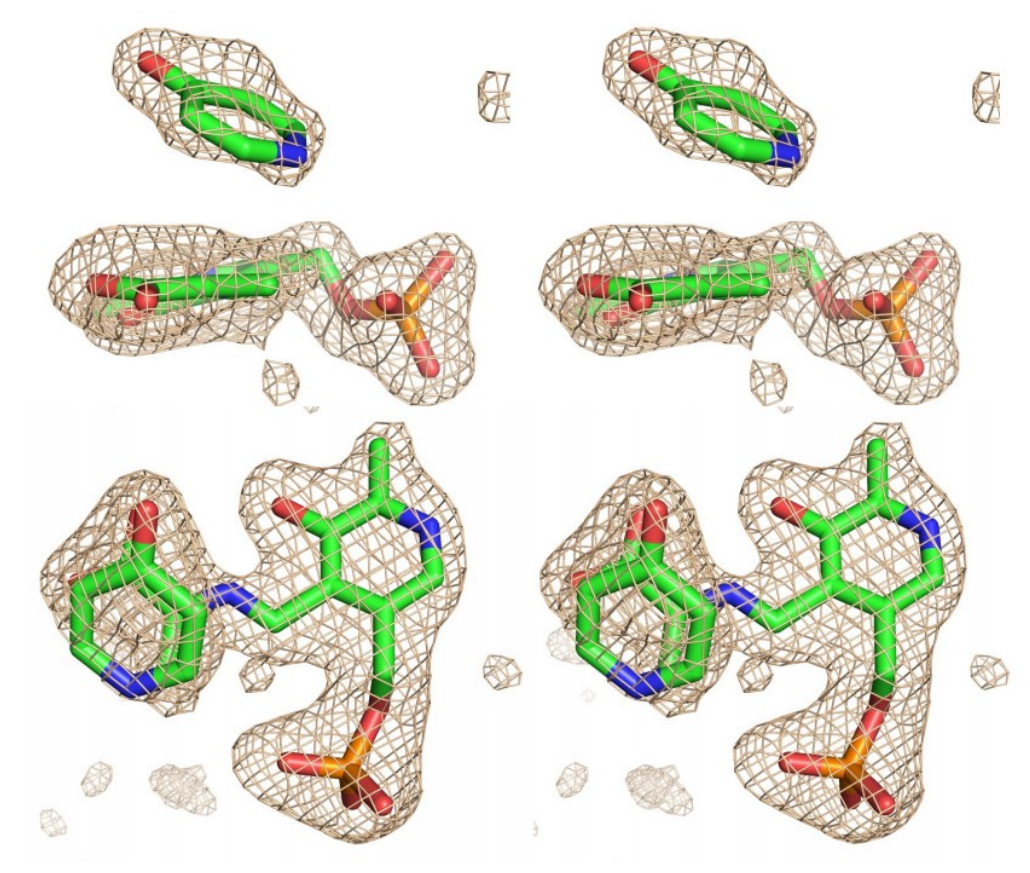

B

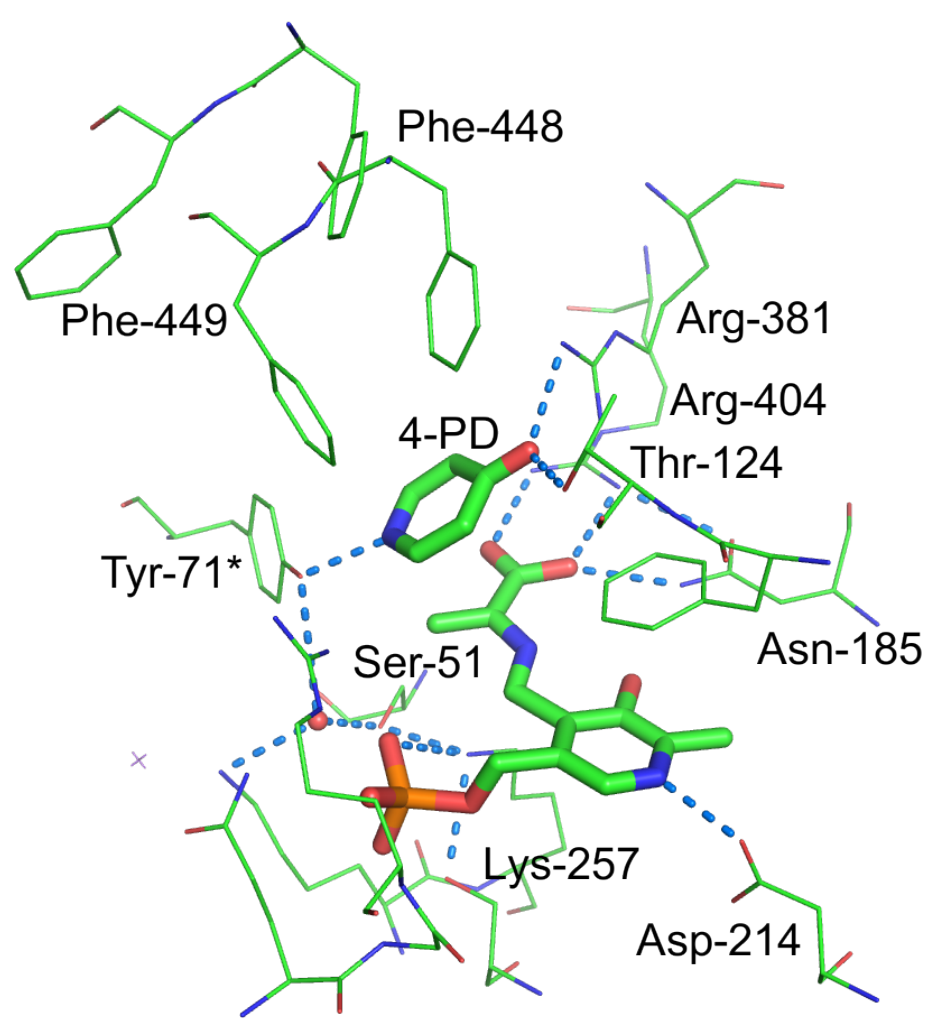

Figure 1. A. Crossed-eye stereo view of the PLP-aminoacrylate complex and 4-PD in chain A of wildtype TPL modeled into the mFo-Dfc simulated omit electron density map contoured at $4 \sigma$. B. Interactions of the PLP-aminoacrylate complex with the active site of TPL in chain A. 
significant remaining electron density in the 2mFo-DFc map at $1 \sigma$ between NZ of Lys-257 and C4' of the PLP of the aminoacrylate complex. The NZ of Lys-257 is hydrogen bonded to OG of Ser-51 (2.6 $\AA$ ), OG of Ser-254 (3.2 $\AA)$, and one of the phosphate oxygens, OP3, (3.2 $\AA$ ). A network of hydrogen bonds connects Lys-257 to Tyr-71*, through Ser-51 and a bound water, as was seen before for quinonoid complexes of TPL ${ }^{10,11}$. The $\alpha$-carboxylate of the aminoacrylate complex (Figure 1B, Figure S2A) is ion paired to ND1 and ND2 of Arg-404 (2.9 $\AA)$ and hydrogen bonded to OG of Thr-49 (2.7 $\AA)$ and ND2 of Asn-185 (2.9 $\AA$ ), as was seen previously for quinonoid complexes of L-alanine, Lmethionine, and L-phenylalanine of TPL ${ }^{10,11}$. Asn-185 was shown previously to stabilize quinonoid intermediates of TPL by hydrogen bonding ${ }^{24}$. The 4-PD N-1 is hydrogen bonded to the OE of Tyr-71* (2.5 $\AA$ ), and the O-4 is hydrogen bonded to OG of Thr-124 (2.8 $)$ ) and NZ of Arg-381 (2.9 $\AA$ ) (Figure $\mathrm{S} 2 \mathrm{~B}$ ). These interactions of 4-PD are very similar to those found previously in the complex of TPL with pyridine-N-oxide and L-alanine ${ }^{8}$, in which the oxygen of pyridine-N-oxide forms hydrogen bonds with Thr-124 and Arg-381. Furthermore, in the quinonoid complexes of 3-F-L-tyrosine with Y71F and F448H TPL, the phenolic oxygen of the substrate forms short hydrogen bonds to Thr-124 and Arg-381 ${ }^{8}$. The N-1 of 4-PD is also located $2.9 \AA$ above $\mathrm{C}_{\beta}$ of the aminoacrylate (Figure 1A). Thus, 4-PD is located in the expected position of the reaction product, phenol, immediately after cleavage of the $\mathrm{C}_{\beta}$ $\mathrm{C}_{\gamma}$ bond. The OE of Tyr-71* is also hydrogen bonded (2.8 $\AA$ ) to NH2 of Arg-100.

Chain A shows significant disorder in the small domain, comprised of residues 14-43, 347-376, and 428-456, that moves toward the large domain to form a closed conformation covering the active site. Refinement of the structure as the closed conformation resulted in significant remaining density in the small domain. Hence, the structure of chain A was refined as an ensemble of open and closed conformations, as was done previously for some quinonoid complexes of TPL ${ }^{11,25}$, and the resulting refined structure is a mixture of open and closed conformations in an approximate 30:70 ratio, respectively. Quinonoid complexes of TPL were found previously to have a similar ratio of open and closed conformations ${ }^{11,25}$. In the closed conformation, the side chains of Phe-448 and Phe-449 are in 
van der Waals contact with 4-PD (Phe-448 CZ is $2.5 \AA$ away from $\mathrm{C} 4$ and $\mathrm{CZ}$ of Phe-449 is $2.5 \AA$ from N1), while in the open conformation, Phe-448 withdraws about $4 \AA$ and Phe-449 rotates out of the active site, with CZ moving more than $8 \AA$. The refined occupancy of 4-PD in the active site is $86 \%$; thus, since the closed conformation is present at $70 \%$, the ligand must be able to bind to the aminoacrylate complex in both open and closed conformations. Two additional large blobs of electron density located near the protein surface were also adequately modeled as 4-PD, although it is unclear if these have any mechanistic significance.

A complex was also prepared by soaking crystals of TPL with $20 \mathrm{mM}$ 3-F-L-tyrosine, a good substrate $^{3}$, and 4-PD. The resulting structure of the aminoacrylate intermediate in chain A (Figure S4A) is very similar to that formed from L-tyrosine, with 4-PD bound and a mixture of open and closed conformations. Chain B is in an open conformation, and there is electron density that fits well to 3-FL-tyrosine (80\% occupancy), which connects from $\mathrm{N} 1$ to $\mathrm{C} 4$ ' of the PLP, and also there is clear electron density between NZ of Lys-257 and C4' of the PLP (Figure S4B). The distance between Lys$257 \mathrm{NZ}$ and PLP C4' is $1.45 \AA$, and the distance from the 3-fluoro-L-tyrosine N and PLP C4' is $1.43 \AA$. The geometry of the $\mathrm{C}_{\alpha}$ of the 3-F-L-tyrosine is tetrahedral. Thus, the ligand in chain B is most likely a gem-diamine complex of 3-F-L-tyrosine (Figure S4C), rather than a mixture of internal and external aldimines. The complex of L-phenylalanine with wild-type TPL was also found previously to have a gem-diamine complex in chain $\mathrm{B}^{11}$. This difference between the structures of the L-tyrosine and 3-F-Ltyrosine complexes of TPL is possibly due to the much higher solubility of 3-F-L-tyrosine in the cryosolvent soak solution (20 mM compared with $\sim 4 \mathrm{mM}$ for L-tyrosine).

We also soaked TPL crystals with $40 \mathrm{mM}$ S-ethyl-L-cysteine and $10 \mathrm{mM}$ 4-PD. The resulting structure has new density consistent with an aminoacrylate complex in both chains A and B. The aminoacrylate structure in chain A is very similar to that formed from L-tyrosine, with 4-PD bound and a 30:70 mixture of open and closed conformations for the small domain. The aminoacrylate structure 
found in chain B is also similar, but there is no electron density for 4-PD, and it is exclusively in an open conformation, as can be seen from the position of Phe-448 and Phe-449 (Figure S5).

Crystals of perdeuterated TPL ( $~ 88 \%$ deuteration of nonexchangeable hydrogens; see Methods for more details) were also soaked with $40 \mathrm{mM}$ S-ethyl-L-cysteine and $10 \mathrm{mM}$ 4-PD. These crystals are more disordered than native TPL, diffracting to lower resolution, possibly because incomplete incorporation of deuterium into the nonexchangeable hydrogen positions results in local heterogeneity. The structure was found to contain an aminoacrylate intermediate in chain A nearly identical to that of the hydrogenous TPL, and is a mixture of open and closed conformations. However, in chain B, there is only an open conformation; new electron density is connected to C4' of the PLP, and Lys-257 is also attached to C4' (Figure S6A). The new electron density was modeled as an aminoacrylate, since the side chain density of the ethanethiol is absent (Figure S6A). The $\mathrm{N}_{\alpha}$-C4' distance is $1.25 \AA$, and the Lys-257 NZ-C4' distance is $1.44 \AA$ in the refined model. Thus, this complex is likely to be a gemdiamine of the aminoacrylate, immediately before product release. The distance between the carboxylate oxygens and Arg-404 is greater (Figure S6B, $3.15 \AA$ ) than in the aminoacrylate Schiff's base complexes (Figures 1, 2.9-3.0 A), and only one nitrogen of Arg-404 interacts, possibly weakening the ionic interaction in preparation for product release.

The structure obtained by soaking wild-type TPL crystals with $0.2 \mathrm{M} \mathrm{L-serine} \mathrm{and} 10 \mathrm{mM}$ 4-PD also has an aminoacrylate structure bound in chain A. Refinement as a mixture of open and closed conformations gave a 30:70 ratio, similar to what was found with L-tyrosine and S-ethyl-L-cysteine. However, chain B has electron density that fits with bound L-serine (85\% occupancy), and there is also strong electron density between C-4' of the PLP and NZ of Lys-257 (Figure S7A). Thus, this site also appears to be in a gem-diamine complex (Figure S7B), as was also seen above with 3-F-L-tyrosine. In this complex, the OG of the bound serine has hydrogen bonds to $\mathrm{OH}$ of Tyr-71* and Arg-100 (Figure S7B). 
A

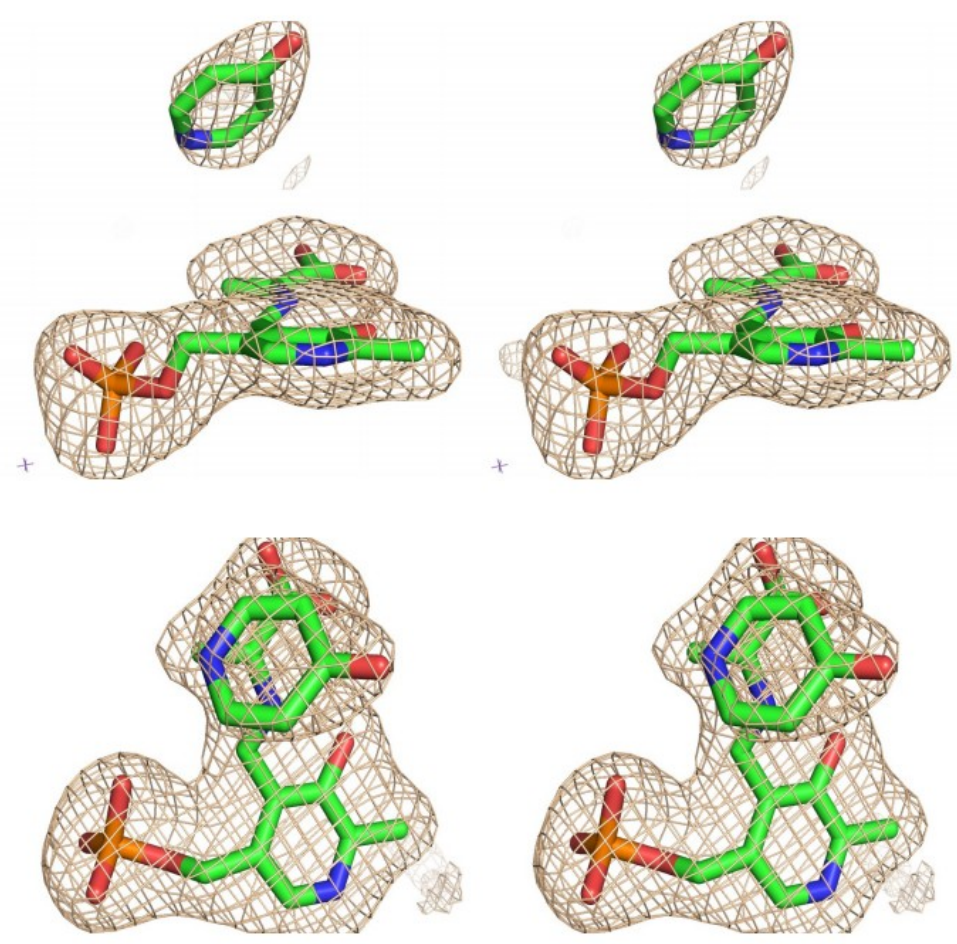

B

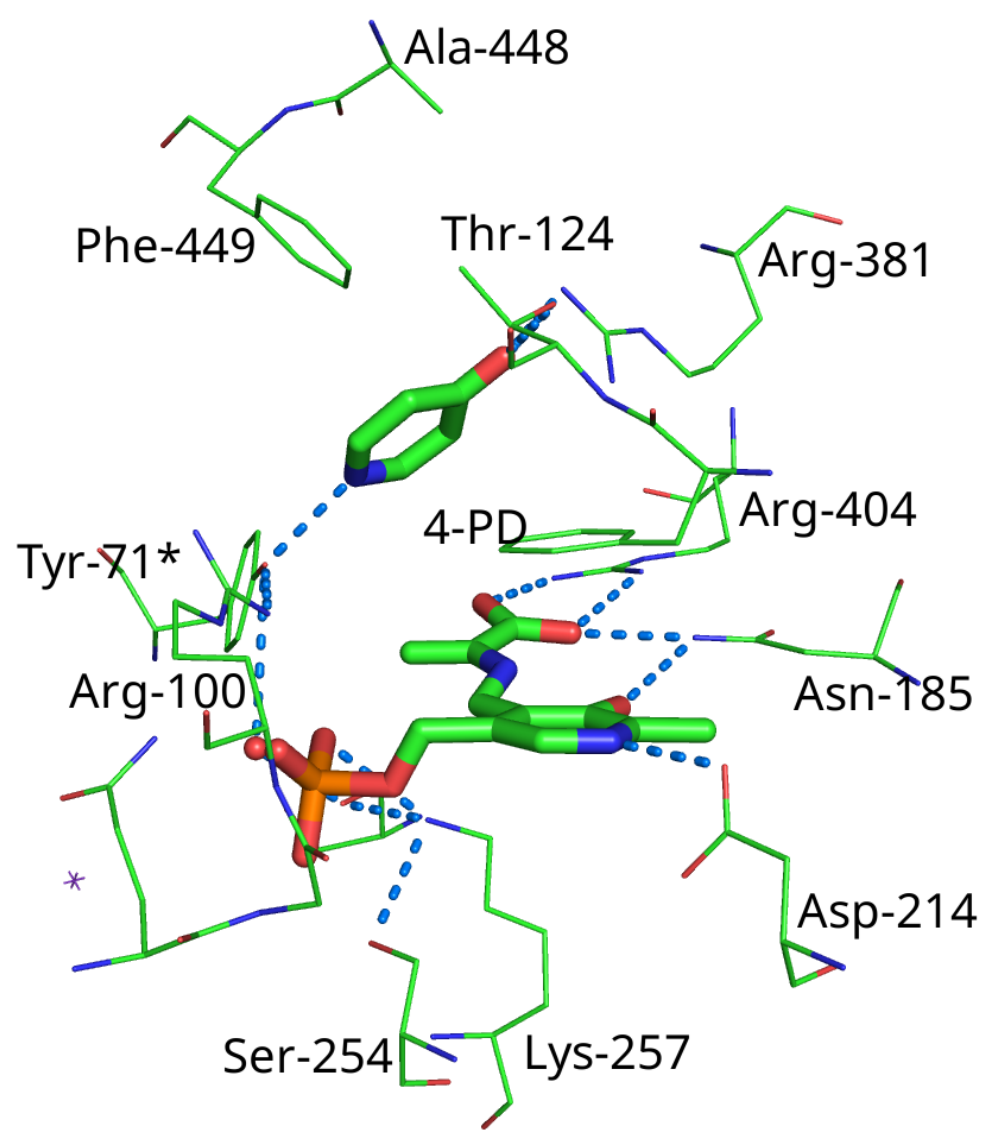

Figure 2. A. Aminoacrylate complex modeled into the mFo-Dfc simulated omit electron density map contoured at $3 \sigma$ for the F448A TPL complex in chain A formed from S-ethyl-L-cysteine and 4-HP. B. Interactions of the aminoacrylate complex with the active site of F448A TPL in chain A. 
Structure of the aminoacrylate complex of F448A TPL from S-ethyl-L-cysteine and 4-hydroxypyridine.

We found previously in rapid-scanning stopped-flow spectroscopic experiments that F448A mutant TPL can form an observable aminoacrylate complex with S-ethyl-L-cysteine, but not with L-tyrosine ${ }^{9}$, 11. Soaking crystals of F448A TPL with S-ethyl-L-cysteine and 4-PD resulted in new electron density in both chain A and chain B that fits well to aminoacrylate complexes (Figure 2A). Similar to what we observed with wild-type TPL, the small domain of chain A has a molecule of 4-PD bound, while chain $\mathrm{B}$ is in an open conformation, without 4-PD bound. We attempted to fit chain A of F448A TPL as a mixture of open and closed conformations, as we did above with wild-type TPL, but we were not successful, possibly due to the lower resolution of F448A TPL crystals ${ }^{11}$. Thus, we modeled chain A as a closed conformation. Similar to wild-type TPL, the N1 of 4-PD is hydrogen bonded to Tyr-71* $(2.7$ $\AA)$, and the O is hydrogen bonded to OG of Thr-124 (2.8 $\AA$ ) and NH2 of Arg-381 (3.0 $\AA)$ in chain A (Figure 2B, Figure S8A). However, the N-1 of 4-PD is located $3.95 \AA$ above $\mathrm{C}_{\beta}$ of the aminoacrylate, an increased distance of about $1 \AA$ compared with wild-type TPL, and the distance from the OH of Tyr71 to $\mathrm{N}-1$ of PD is increased from 2.5 to $2.7 \AA$ (Figure S8B). The carboxylate of the aminoacrylate is ion-paired with the guanidinium of Arg-404 and hydrogen bonded to ND2 of Asn-185 and OG of Thr49. Phe-449 is almost perpendicular to 4-PD, and CZ is $3.4 \AA$ from $\mathrm{C} 4$ of 4-PD. The structure of the complex in chain B is very similar to that of the B chain of wild-type TPL, with an aminoacrylate structure in the open conformation and no 4-PD bound.

Kinetics of aminoacrylate intermediate formation of wild-type TPL from L-tyrosine and 4hydroxypyridine. When TPL is mixed with $2 \mathrm{mM}$ L-tyrosine and $10 \mathrm{mM}$ 4-HP in the stopped-flow spectrophotometer in phosphate buffer at $\mathrm{pH} 8$, a new absorption peak with $\lambda_{\max }$ at $338 \mathrm{~nm}$ is formed which is assigned to the aminoacrylate intermediate (Figure 3A). Initially, there is rapid formation (1/ $\tau \sim 100 \mathrm{~s}^{-1}$ ) of a weakly absorbing band at $502 \mathrm{~nm}$, attributed to a quinonoid intermediate ${ }^{3,5,9,11,12,26}$. 


$$
\mathrm{E}+\mathrm{S} \stackrel{\mathrm{K}_{1}}{\rightleftharpoons} \mathrm{E}_{\mathrm{AL}} \stackrel{\mathrm{k}_{2}}{\underset{\mathrm{k}_{-2}}{\rightleftharpoons}} \mathrm{E}_{\mathrm{Q}} \stackrel{\mathrm{k}_{3}}{\underset{\mathrm{k}_{-3}}{\rightleftharpoons}} \mathrm{E}_{\mathrm{AA}}+4-\mathrm{PD} \stackrel{\mathrm{K}_{4}}{\rightleftharpoons} \mathrm{E}_{\mathrm{AA}} \cdot 4-\mathrm{PD}
$$

The simplest mechanism for reaction of TPL with substrates is shown in Eqn. 7, where $\mathrm{E}_{\mathrm{AL}}$ is the external aldimine, $\mathrm{E}_{\mathrm{Q}}$ is the quinonoid intermediate, and $\mathrm{E}_{\mathrm{AA}}$ is the aminoacrylate intermediate. For this mechanism, the first observable relaxation, $1 / \tau_{1}$, is given by Eqn. 8 and the second observable relaxation, $1 / \tau_{2}$, is given by Eqn. 9 .

$$
\begin{aligned}
& 1 / \tau_{1}=\mathrm{k}_{2} *[\mathrm{~S}] /\left(\mathrm{K}_{1}+[\mathrm{S}]\right)+\mathrm{k}_{-2} \\
& 1 / \tau_{2}=\mathrm{k}_{3} * \mathrm{~K}_{4} /\left(\mathrm{K}_{4}+[4 \mathrm{PD}]\right)+\mathrm{k}_{-3}
\end{aligned}
$$

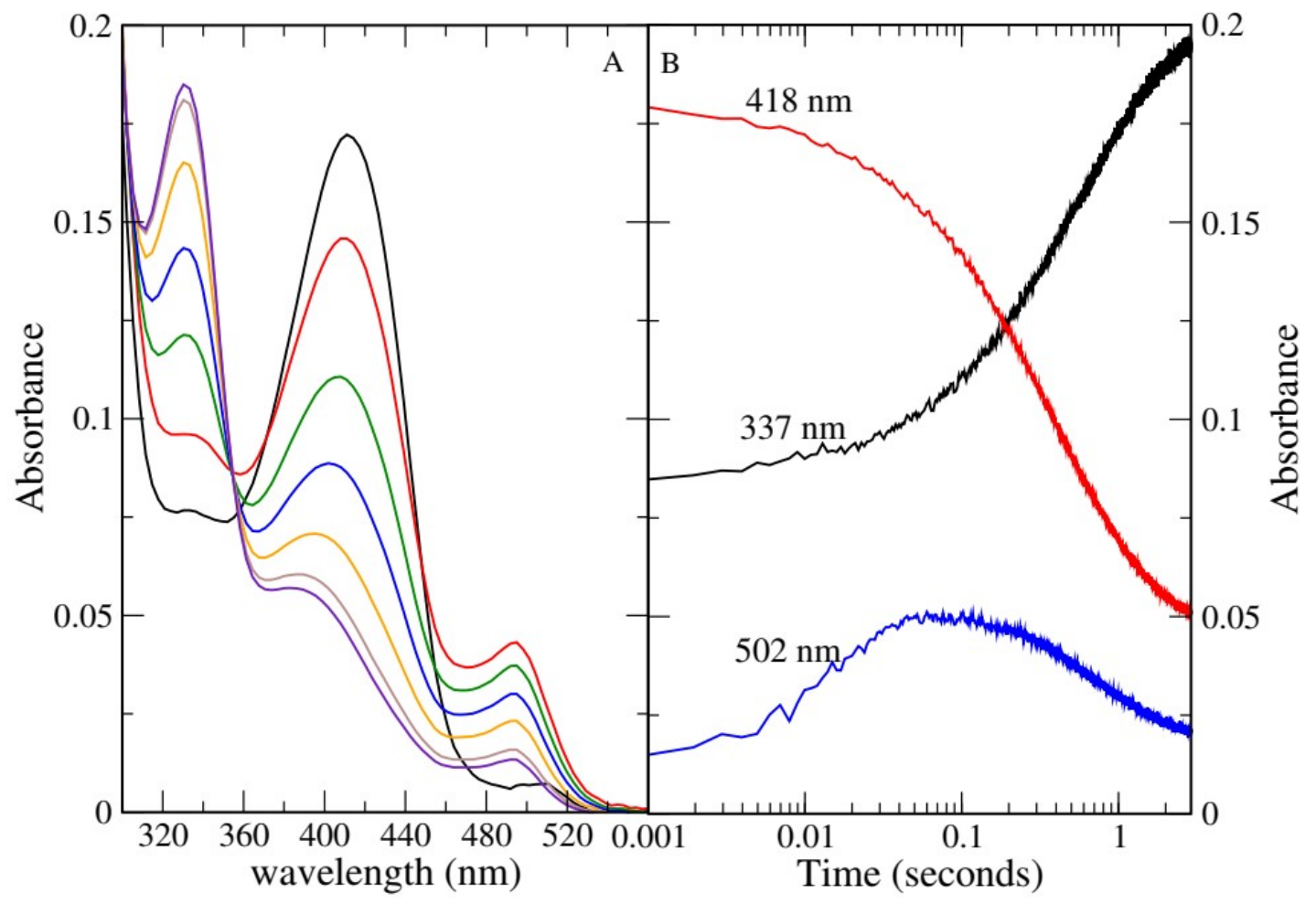

Figure 3. Rapid-scanning stopped-flow measurements of the reaction of wild-type TPL with L-tyrosine and 4-PD. The reactions contained $20 \mu \mathrm{M}$ TPL, $2 \mathrm{mM}$ L-tyrosine, and $10 \mathrm{mM}$ 4-PD in $0.05 \mathrm{M}$ potassium phosphate, $\mathrm{pH} 8.0$ at $295 \mathrm{~K}$. A. Representative scans collected during the reaction. The scans were collected at $0.002 \mathrm{sec}$ (black), $0.095 \mathrm{sec}$ (red), $0.292 \mathrm{sec}$ (green), $0.582 \mathrm{sec}$ (blue), $0.872 \mathrm{sec}$ (orange), $1.452 \mathrm{sec}$ (brown) and $2.612 \mathrm{sec}$ (violet). B. Time courses at $337 \mathrm{~nm}$ (black), $418 \mathrm{~nm}$ (red) and $502 \mathrm{~nm}$ (blue). 
The formation of the aminoacrylate intermediate shows biphasic kinetics in phosphate buffer, as seen before ${ }^{12}$. Decay of the external aldimine at $420 \mathrm{~nm}$ and quinonoid intermediate at $502 \mathrm{~nm}$ and formation of the aminoacrylate at $338 \mathrm{~nm}$ follows identical kinetics (Figure 3B). There is a clear isosbestic point at $360 \mathrm{~nm}$ between the $338 \mathrm{~nm}$ peak of the aminoacrylate and the $418 \mathrm{~nm}$ peak of the external aldimine during the decay, indicating that the external aldimine and quinonoid complexes are in rapid equilibrium, and there is direct reaction of the quinonoid to the aminoacrylate. Similar data are obtained in triethanolamine buffer at $\mathrm{pH} \mathrm{8,} \mathrm{which} \mathrm{is} \mathrm{required} \mathrm{for} \mathrm{high} \mathrm{pressure} \mathrm{experiments;} \mathrm{however,}$ the decay of the $418 \mathrm{~nm}$ intermediate and formation of the $338 \mathrm{~nm}$ aminoacrylate complex occurs in only one exponential phase.

Kinetics of aminoacrylate intermediate formation of wild-type TPL from S-ethyl-L-cysteine and 4hydroxypyridine. Mixing of wild-type TPL with $40 \mathrm{mM}$ S-ethyl-L-cysteine and $10 \mathrm{mM}$ 4-PD in phosphate buffer at $\mathrm{pH} 8$ results in rapid formation of a strong absorbance peak at $505 \mathrm{~nm}$, which subsequently decays concomitant with formation of a new peak at $342 \mathrm{~nm}$ (Figure 4A). Similar data were obtained when the reaction was performed in triethanolamine buffer. There is an isosbestic point at about $362 \mathrm{~nm}$ between the $505 \mathrm{~nm}$ peak and the $342 \mathrm{~nm}$ peak, indicating that there is direct conversion of the quinonoid intermediate (505 nm species) to the aminoacrylate (342 $\mathrm{nm}$ species). The decay of the quinonoid intermediate is biphasic under these conditions ${ }^{12}$. The observed rate constants for the second $\left(1 / \tau_{2}\right)$ and third $\left(1 / \tau_{3}\right)$ kinetic phases (both describing the quinonoid decay) display opposite behavior as [4-PD] is increased; with $k_{\mathrm{obs}}$ on $1 / \tau_{2}$ decreasing, as expected from Eqn. 9 , and $k_{\mathrm{obs}}$ on $1 / \tau_{3}$ increasing ${ }^{12}$. This is consistent with a mechanism with a first step of aminoacrylate formation, followed by rapid equilibrium binding of 4-PD, as shown in Eqn. 7, and a rearrangement of the aminoacrylate following 4-PD binding. F448A TPL also exhibits similar spectra after mixing with Sethyl-L-cysteine and 4-PD, although the peaks at $505 \mathrm{~nm}$ and $338 \mathrm{~nm}$ are less prominent than for wildtype TPL, as was shown previously ${ }^{9}$. 


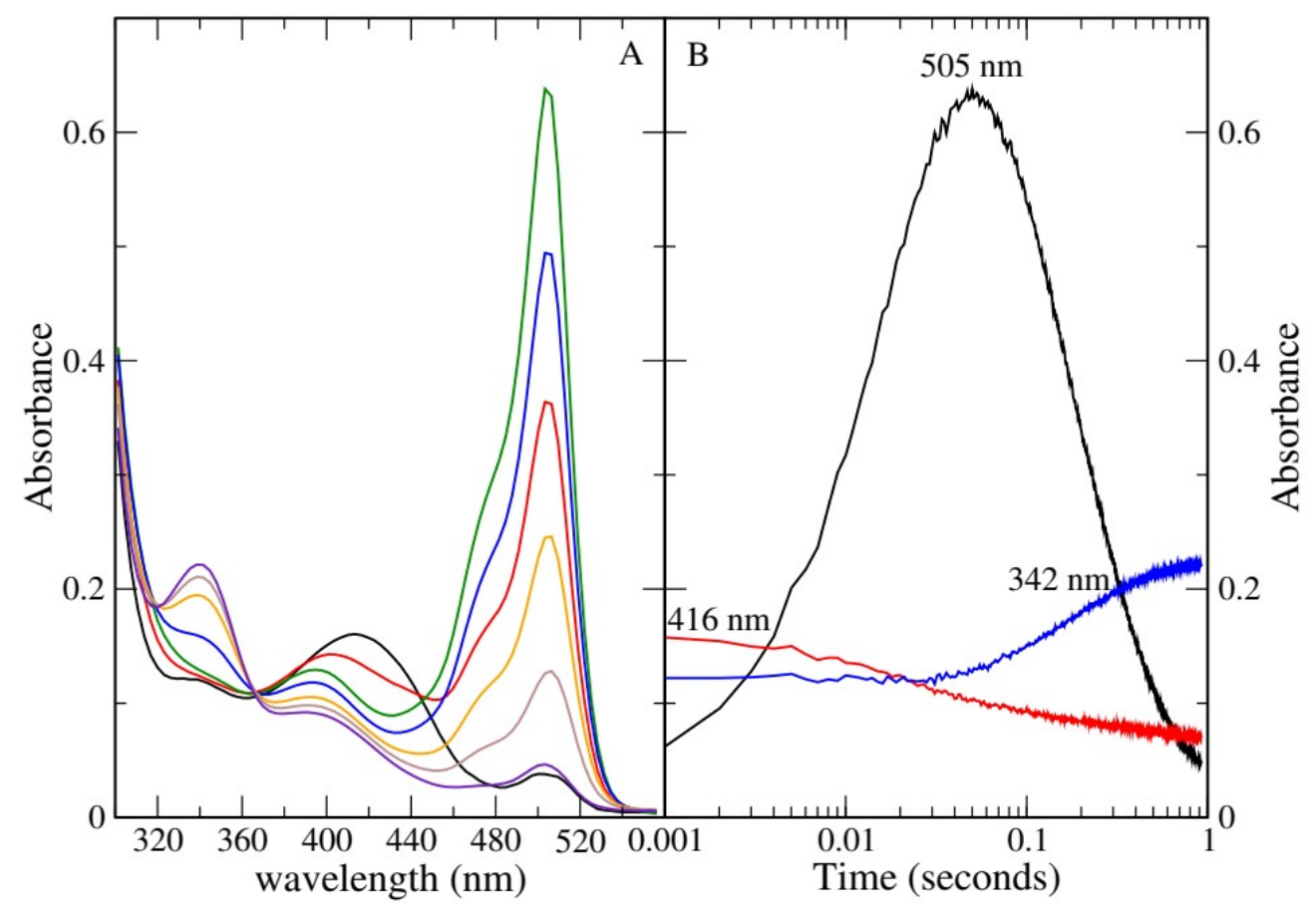

Figure 4. Stopped-flow measurements of the reaction of wild-type TPL with S-ethyl-L-cysteine and 4PD. The reactions contained $20 \mu \mathrm{M}$ TPL, $20 \mathrm{mM}$ S-ethyl-L-cysteine, and $10 \mathrm{mM}$ 4-PD in $0.05 \mathrm{M}$ potassium phosphate, $\mathrm{pH}$ 8.0. A. Representative scans collected during the reaction. The scans were collected at $0.002 \mathrm{sec}$ (black), $0.095 \mathrm{sec}$ (red), $0.292 \mathrm{sec}$ (green), $0.582 \mathrm{sec}$ (blue), $0.872 \mathrm{sec}$ (orange), $1.452 \mathrm{sec}$ (brown) and $2.612 \mathrm{sec}$ (violet). B. Time courses at $342 \mathrm{~nm}$ (blue), $416 \mathrm{~nm}$ (red) and $505 \mathrm{~nm}$ (black).

Temperature dependent kinetics of aminoacrylate intermediate formation of wild-type and F448A TPL.

The reactions were performed in $0.05 \mathrm{M}$ potassium phosphate, $\mathrm{pH} 8.0$, at temperatures from 281 to 318 $\mathrm{K}$, collecting data at $410 \mathrm{~nm}$ for L-tyrosine (Figure 3) and $505 \mathrm{~nm}$ for S-ethyl-L-cysteine (Figure 4). Typical data at each temperature are shown in Figures S9 and S10. Note that the first order rate constant for formation of the aminoacrylate intermediate is not dependent on the L-tyrosine or S-ethylL-cysteine concentration, but is affected by the [4-PD] ${ }^{12}$, as shown by Eqn. 9. 4-PD was found previously to bind with an apparent $K_{\mathrm{d}}$ of about $1 \mathrm{mM}^{12}$. In the present experiments, $10 \mathrm{mM} 4-\mathrm{PD}$ was used, so the rates are $>90 \%$ saturated. Most of the reactions show an obvious nonlinear dependence of $\ln (k)$ on temperature (non-Arrhenius behavior; Figure 5). Non-Arrhenius behavior can arise for a number of reasons, including a change in rate-limiting step and enzyme denaturation. We have chosen 

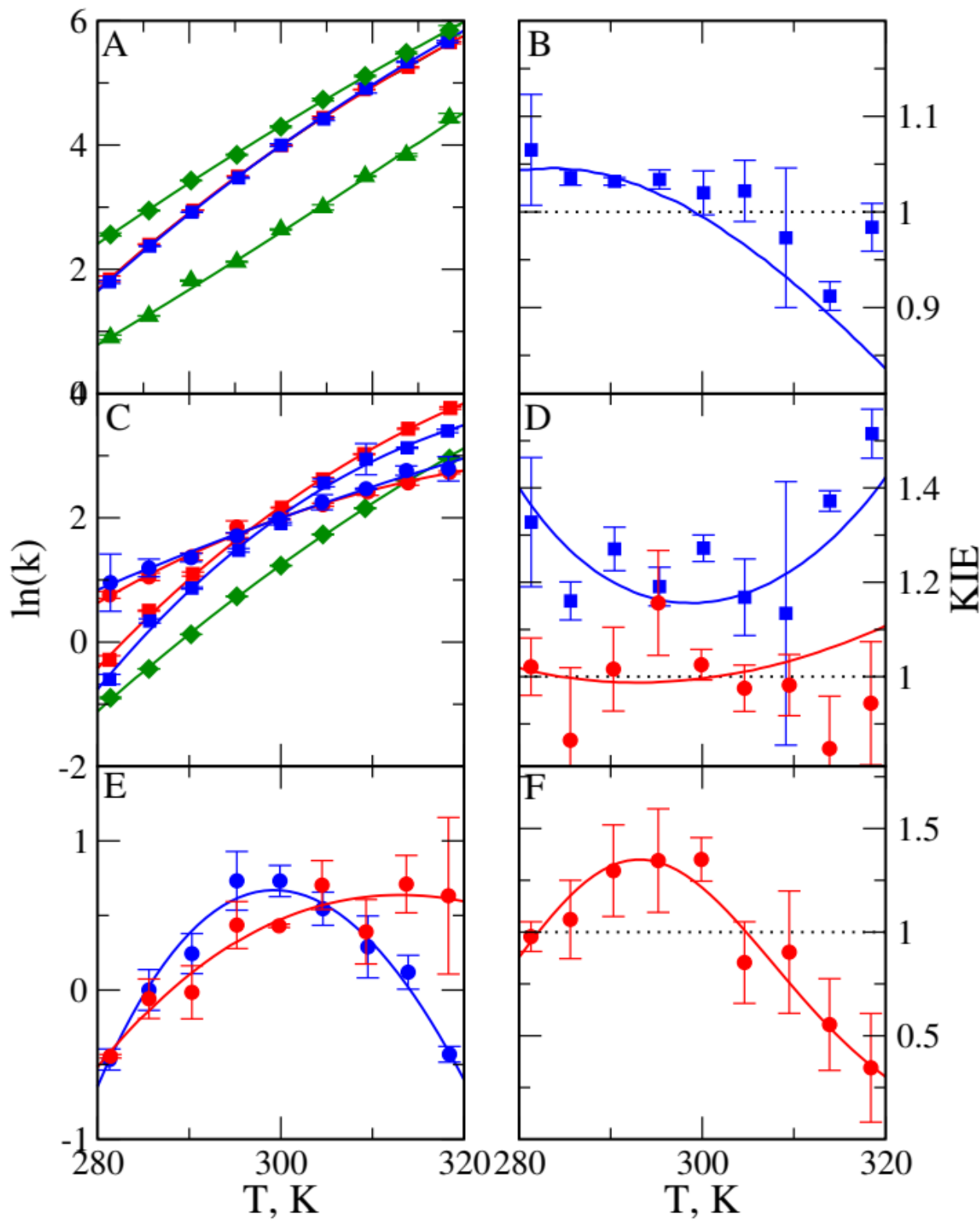

Figure 5. Effects of temperature on quinonoid and aminoacrylate intermediate formation by TPL. In all cases, the lines are the calculated fits to Equation 5 with the parameters given in Table 1. A. Effect of temperature on the formation of the quinonoid intermediate $\left(1 / \tau_{1}\right)$ of TPL with S-ethyl-L-cysteine. Red squares, wild-type TPL; blue squares, perdeuterated TPL; green diamonds, first phase of quinonoid intermediate formation by F448A TPL; green triangles, second phase of quinonoid intermediate formation by F448A TPL. B. Heavy enzyme deuterium KIE on quinonoid intermediate formation from S-ethyl-L-cysteine. C. Effect of temperature on formation of the aminoacrylate intermediates $\left(1 / \tau_{2}\right)$ of wild-type, perdeuterated and F448A TPL from L-tyrosine and S-ethyl-Lcysteine. Red circles, wild-type TPL with L-tyrosine; blue circles, perdeuterated TPL with L-tyrosine; blue squares, wild-type TPL with S-ethyl-L-cysteine; red squares, perdeuterated TPL with S-ethyl-Lcysteine; green diamonds, F448A TPL. D. Heavy enzyme KIE on aminoacrylate intermediate $\left(1 / \tau_{2}\right)$ formation. Squares and blue line, S-ethyl-L-cysteine; circles and red line, L-tyrosine. E. Effect of temperature on the slow phase of aminoacrylate formation $\left(1 / \tau_{3}\right)$ of wild-type TPL from L-tyrosine. Blue circles, wild-type TPL and L-tyrosine; red circles, perdeuterated TPL and L-tyrosine. F. Heavy enzyme deuterium KIE on $1 / \tau_{3}$. Circles and red line, L-tyrosine. 
to describe these data using the macromolecular rate theory (MMRT) equation (Eqn. 5) ${ }^{21}$ as it gives a good fit to the data (Figure 5) and allows a quantitative comparison of the temperature dependence of each enzyme reaction studied here (Table 1). It should be noted that if the binding of 4-PD weakens with increasing temperature, the observed relaxation rate constant, $1 / \tau_{2}$, would be expected to show a nonlinear upward curvature, rather than downward as is observed. Further, if some of the nonArrhenius behavior is caused by a change in substrate saturation (and thus rate-limiting step), this effect should largely cancel in the KIEs as substrate capture should not be significantly isotope dependent. The results of fitting are given in Table 1, and the data points in Figure 5 used for the fitting are given in Table S2. Because of the small amplitude of the quinonoid intermediate at $505 \mathrm{~nm}$ for L-tyrosine (Figure 3), we did not analyze the temperature dependence of the fast phase $\left(1 / \tau_{1}\right)$. The first phase of the reaction of L-tyrosine to form an aminoacrylate has small positive values of $\Delta H^{\ddagger}$, but large negative values of $\Delta S^{\ddagger}$, suggesting that the transition state for elimination of phenol is highly ordered for Ltyrosine. Furthermore, the second phase of aminoacrylate intermediate formation with L-tyrosine (1/ $\tau_{3}$ ) shows strong curvature (Figure 5E), resulting from a large negative value of the apparent $\Delta C_{\mathrm{p}}^{\ddagger}$ (heat capacity). The reaction with perdeuterated TPL shows a significantly reduced $\Delta C_{\mathrm{p}}^{\ddagger}$ and $\Delta H^{\ddagger}$, and an increase in $\Delta S^{\ddagger}$ (Table 1). There is no significant KIE on the first phase of aminoacrylate formation with perdeuterated TPL and L-tyrosine, but there is a small normal KIE $(1.4 \pm 0.2)$ on the second phase at $295 \mathrm{~K}$ (Figure 5F), which becomes inverse at higher temperatures.

For S-ethyl-L-cysteine, we could readily determine the effect of temperature on both quinonoid intermediate $\left(1 / \tau_{1}\right)$ and aminoacrylate intermediate formation $\left(1 / \tau_{2}\right)$ at $505 \mathrm{~nm}$. In contrast to the reactions of L-tyrosine, these reactions all have much larger values of $\Delta H^{\ddagger}$, and positive values of $\Delta S^{\sharp}$ (Table 1). $\Delta C_{\mathrm{p}}^{\ddagger}$ is very similar for quinonoid intermediate formation with native and perdeuterated TPL, but it increases for aminoacrylate formation by perdeuterated TPL. There is no significant KIE on quinonoid intermediate formation below $310 \mathrm{~K}$, but at higher temperature there is a small inverse 
KIE (Figure 5B). There is a normal KIE $(1.20 \pm 0.04)$ at $300 \mathrm{~K}$ on aminoacrylate formation (Figure 5D), which increases at higher temperatures. Formation of the quinonoid intermediate from S-ethyl-Lcysteine by F448A TPL shows a decrease in $\Delta H^{\ddagger}$ and $\Delta S^{\ddagger}$ compared to wild-type TPL, but no difference in $\Delta C_{\mathrm{p}}$. In contrast to wild-type TPL, F448A TPL exhibits biphasic formation of the $505 \mathrm{~nm}$ quinonoid intermediate (Figure 5A, green diamonds and triangles). The fast phase is slightly faster than that of wild-type TPL, while the second phase is slower. Aminoacrylate formation by F448A TPL, in this case, $1 / \tau_{3}$, shows a decrease in $\Delta S^{\ddagger}$, but little difference in $\Delta H^{\ddagger}$ and $\Delta C_{\mathrm{p}}^{\ddagger}$.

Table 1

Effects of temperature on TPL kinetics

\begin{tabular}{|c|c|c|c|c|c|c|}
\hline Reaction & $\Delta H^{+}, \mathrm{kJ} / \mathrm{mol}$ & $\Delta \Delta H^{\ddagger}, \mathrm{kJ} / \mathrm{mol}$ & $\Delta S^{\ddagger}, \mathrm{J} / \mathrm{mol}-\mathrm{K}$ & $\Delta \Delta S^{\ddagger}, \mathrm{J} / \mathrm{mol}-\mathrm{K}$ & $\Delta C_{\mathrm{p}}^{\ddagger}, \mathrm{kJ} / \mathrm{mol}-\mathrm{K}$ & $\Delta \Delta C_{\mathrm{p}}^{\ddagger}, \mathrm{kJ} / \mathrm{mol}-\mathrm{K}$ \\
\hline TPL+Tyr, $1 / \tau_{2}$ & $+38.1 \pm 1.1$ & & $-100 \pm 4$ & & $-0.88 \pm 0.23$ & \\
\hline TPL+Tyr, $1 / \tau_{3}$ & $+3.2 \pm 1.5$ & & $-228 \pm 10$ & & $-4.8 \pm 0.5$ & \\
\hline$\left[{ }^{2} \mathrm{H}\right]-\mathrm{TPL}+\mathrm{Tyr}, 1 / \tau_{2}$ & $+39.4 \pm 0.5$ & $+1.3 \pm 1.2^{\mathrm{a}}$ & $-96.8 \pm 4.7$ & $+3.2 \pm 6.2^{\mathrm{a}}$ & $-0.63 \pm 0.57$ & $+0.25 \pm 0.31^{\mathrm{a}}$ \\
\hline$\left[{ }^{2} \mathrm{H}\right]-\mathrm{TPL}+\mathrm{Tyr}, 1 / \tau_{3}$ & $+19.7 \pm 0.4$ & $+16.5 \pm 1.6^{\mathrm{a}}$ & $-175 \pm 4$ & $+53 \pm 10.8^{\mathrm{a}}$ & $-1.49 \pm 0.56$ & $+3.31 \pm 0.75^{\mathrm{a}}$ \\
\hline TPL+S-Et-Cys, $1 / \tau_{1}$ & $+74.1 \pm 0.4$ & & $+35.3 \pm 1.3$ & & $-0.53 \pm 0.07$ & \\
\hline TPL+S-Et-Cys, $1 / \tau_{2}$ & $+78.2 \pm 1.0$ & & $+33.9 \pm 3.5$ & & $-1.22 \pm 0.20$ & \\
\hline$\left[{ }^{2} \mathrm{H}\right]-\mathrm{TPL}+\mathrm{S}-\mathrm{Et}-\mathrm{Cys}, 1 / \tau_{1}$ & $+76.1 \pm 0.5$ & $+3.9 \pm 0.8^{\mathrm{a}}$ & $+41.9 \pm 1.8$ & $+12.9 \pm 3.8^{\mathrm{a}}$ & $-0.41 \pm 0.10$ & $+0.27 \pm 0.22^{\mathrm{a}}$ \\
\hline$\left[{ }^{2} \mathrm{H}\right]-\mathrm{TPL}+\mathrm{S}-\mathrm{Et}-\mathrm{Cys}, 1 / \tau_{2}$ & $+75.9 \pm 1.7$ & $-5.3 \pm 2.9^{\mathrm{a}}$ & $+24.4 \pm 4.1$ & $-19.4 \pm 10^{\mathrm{a}}$ & $-1.49 \pm 0.13$ & $-1.02 \pm 0.55^{\mathrm{a}}$ \\
\hline F448A TPL+S-Et-Cys, $1 / \tau_{1}$ & $+64.1 \pm 0.4$ & $-15.8 \pm 1.3^{\mathrm{b}}$ & $+4.5 \pm 1.5$ & $-49.3 \pm 5.1^{b}$ & 0 & $-0.28 \pm 0.3^{\mathrm{b}}$ \\
\hline F448A TPL+S-Et-Cys, $1 / \tau_{2}$ & $+66.4 \pm 1.5$ & & 0 & & $+0.68 \pm 0.28$ & \\
\hline F448A TPL+S-Et-Cys, $1 / \tau_{3}$ & $+76.6 \pm 0.6$ & & $+20.7 \pm 2.1$ & & $-0.37 \pm 0.12$ & \\
\hline
\end{tabular}

${ }^{\mathrm{a}}\left[{ }^{2} \mathrm{H}\right]-\mathrm{TPL}-\mathrm{TPL}$

${ }^{\mathrm{b}} \mathrm{F} 448 \mathrm{~A}$ TPL-TPL

Pressure dependent kinetics of aminoacrylate intermediate formation of wild type and F448A TPL.

The reactions were performed at $293 \mathrm{~K}$ in single wavelength mode, by following the absorbance change at $410 \mathrm{~nm}$ for the reaction of L-tyrosine and $505 \mathrm{~nm}$ for the reaction of S-ethyl-L-cysteine. Triethanolamine buffer was used for the high pressure experiments, since it has a much smaller $\Delta \mathrm{p} K_{a}$ with pressure than phosphate. For L-tyrosine, we only analyzed the formation of the aminoacrylate (1/ 
$\left.\tau_{2}\right)$, due to the low amplitude of the first phase $\left(1 / \tau_{1}\right)$. Due to the relatively large amplitudes of the intermediates for S-ethyl-L-cysteine (Figure 4), we analyzed both formation of the quinonoid
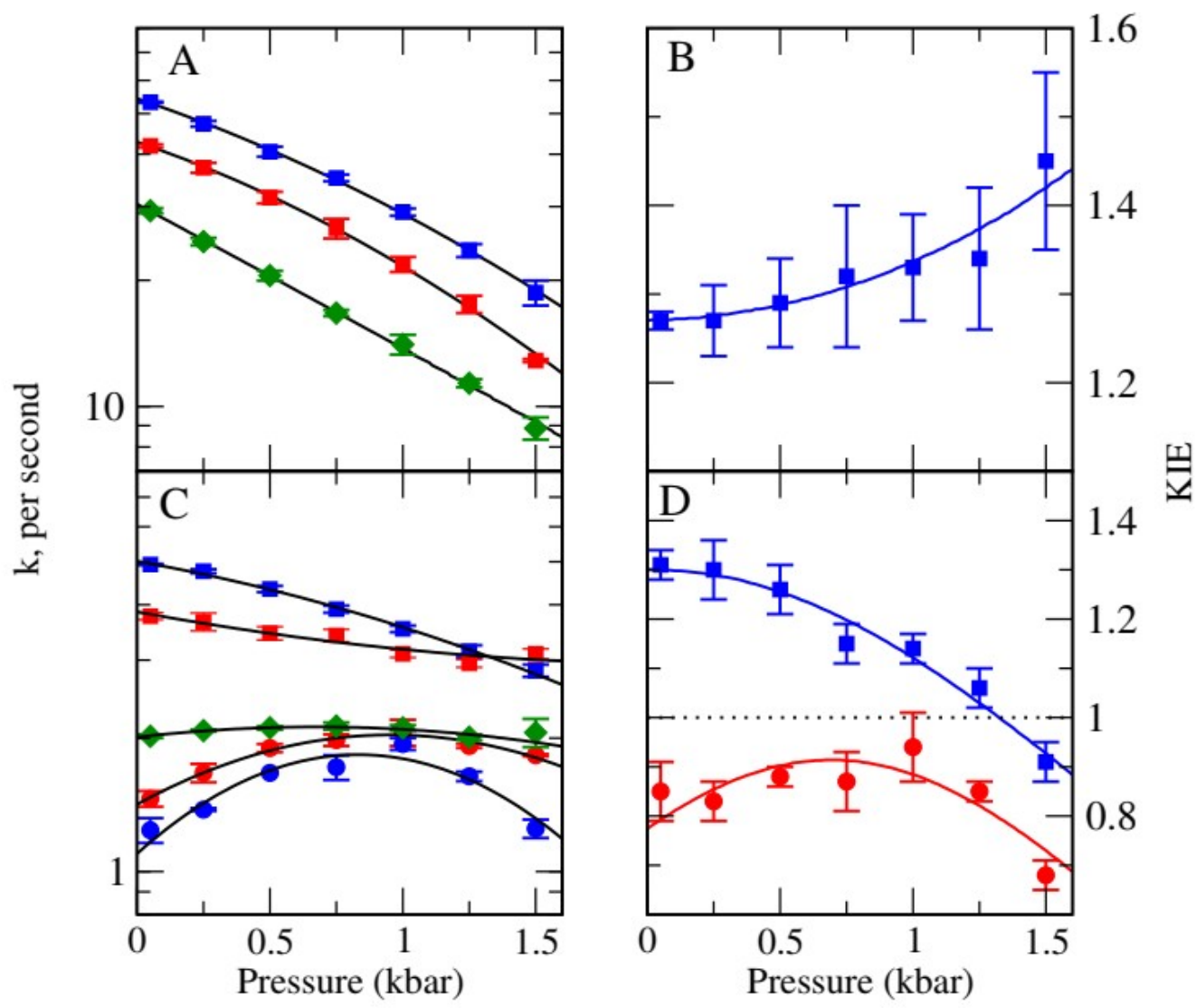

Figure 6. Effects of hydrostatic pressure on quinonoid and aminoacrylate intermediate formation by TPL. In all cases, the lines are the calculated fits to Equation 6 with the parameters given in Table 2. A. Effect of pressure on the formation of the quinonoid intermediate $\left(1 / \tau_{1}\right)$ of TPL with S-ethyl-L-cysteine. Blue squares, wild-type TPL; red squares, perdeuterated TPL; green diamonds, F448A TPL. B: Heavy enzyme deuterium KIE on $1 / \tau_{1}$ as a function of pressure. C. Effect of pressure on formation of the aminoacrylate intermediates $\left(1 / \tau_{2}\right)$ of wild-type, perdeuterated and F448A TPL from L-tyrosine and Sethyl-L-cysteine. Blue squares: wild-type TPL and S-ethyl-L-cysteine; Red squares, perdeuterated TPL and S-ethyl-L-cysteine; Blue circles, wild-type TPL and L-tyrosine; Red circles, perdeuterated TPL and L-tyrosine; Green diamonds, F448A TPL and S-ethyl-L-cysteine. D: Heavy enzyme deuterium KIE on $1 / \tau_{2}$ as a function of pressure. Red circles, tyrosine; Blue squares, S-ethyl-L-cysteine.

intermediate $\left(1 / \tau_{1}\right)$ and subsequent decay to the aminoacylate $\left(1 / \tau_{2}\right)$. Typical kinetic traces are presented in Figure S11 and S12, and the data points in Figure 6 are given in Table S3. The results of fitting the pressure dependent data to Eqn. 6 are shown in Table 2. The rate constant for formation of the quinonoid intermediate from S-ethyl-L-cysteine decreases with increasing pressure (Figure 6A), while the perdeuterated enzyme shows a normal heavy enzyme deuterium KIE of 1.3-1.4 which 
increases with pressure (Figure 6B). In contrast, F448A TPL shows no curvature in the plot, so its compressibility is zero. Formation of the aminoacrylate intermediate from L-tyrosine shows downward curvature (Figure 6C), as a result of a large negative compressibility, $\Delta \beta^{\ddagger}$. There is an inverse isotope effect of about 0.8 at 1 bar, which is very pressure dependent (Figure 6D) and gives rise to large values of $\Delta \Delta V^{\ddagger}$ and $\Delta \Delta \beta^{\ddagger}$ (Table 2). For aminoacrylate formation from S-ethyl-L-cysteine, there is much less curvature in the plots because of smaller negative $\Delta \beta^{\star}$. There is a normal isotope effect on the reaction at $1 \mathrm{bar}$, but it reduces with increasing pressure and becomes inverse at $1.5 \mathrm{kbar}$.

Table 2

Effects of hydrostatic pressure on TPL kinetics at $293 \mathrm{~K}$

\begin{tabular}{|c|c|c|c|c|c|c|c|c|c|}
\hline Reaction & $\begin{array}{l}1 / \tau_{1} \\
\mathrm{~s}^{-1}\end{array}$ & $\begin{array}{l}\Delta V^{*} \\
\mathrm{~mL} / \mathrm{mol}\end{array}$ & $\begin{array}{l}\quad \Delta \beta^{\ddagger} \\
\mathrm{ml} / \mathrm{mol}- \\
\mathrm{kbar}\end{array}$ & $\begin{array}{l}1 / \tau_{2} \\
\mathrm{~s}^{-1}\end{array}$ & $\begin{array}{c}\Delta V^{*} \\
\mathrm{~mL} / \mathrm{mol}\end{array}$ & $\begin{array}{l}\Delta \beta^{\ddagger} \\
\mathrm{ml} / \mathrm{mol}-\mathrm{kbar}\end{array}$ & $\begin{array}{l}1 / \tau_{3} \\
\mathrm{~s}^{-1}\end{array}$ & $\begin{array}{c}\Delta V^{\ddagger} \\
\mathrm{mL} / \mathrm{mol}\end{array}$ & $\begin{array}{l}\Delta \beta^{\ddagger} \\
\mathrm{ml} / \mathrm{mol}-\mathrm{kbar}\end{array}$ \\
\hline TPL $+\mathrm{L}-\mathrm{Tyr}$ & $\mathrm{nd}^{\mathrm{a}}$ & $\mathrm{nd}^{\mathrm{a}}$ & $\mathrm{nd}^{\mathrm{a}}$ & $1.10 \pm 0.09$ & $-30.1 \pm 5.5$ & $-36 \pm 7$ & $\mathrm{nd}^{\mathrm{a}}$ & $\mathrm{nd}^{\mathrm{a}}$ & $\mathrm{nd}^{\mathrm{a}}$ \\
\hline $\begin{array}{l}{\left[{ }^{2} \mathrm{H}\right]-\mathrm{TPL}+\mathrm{L}-} \\
\text { Tyr }\end{array}$ & $\mathrm{nd}^{\mathrm{a}}$ & $\mathrm{nd}^{\mathrm{a}}$ & $\mathrm{nd}^{\mathrm{a}}$ & $1.42 \pm 0.03$ & $\begin{array}{c}-18.5 \pm 1.4 \\
(+11.6 \pm 6.9) \\
\mathrm{b}\end{array}$ & $\begin{array}{c}-19 \pm 7 \\
(+17 \pm 14)^{b}\end{array}$ & $\mathrm{nd}^{\mathrm{a}}$ & $\mathrm{nd}^{\mathrm{a}}$ & $\mathrm{nd}^{\mathrm{a}}$ \\
\hline $\begin{array}{l}\text { TPL+S-Et- } \\
\text { L-Cys }\end{array}$ & $54.3 \pm 0.4$ & $12.0 \pm 0.8$ & $-6.8 \pm 1.2$ & $5.01 \pm 0.02$ & $6.0 \pm 0.9$ & $-4.7 \pm 1.7$ & $\begin{array}{c}1.53 \pm \\
0.01\end{array}$ & $21.8 \pm 1.5$ & $4.0 \pm 1.0$ \\
\hline $\begin{array}{l}{\left[{ }^{2} \mathrm{H}\right]-\mathrm{TPL}+\mathrm{S}-} \\
\text { Et-L-Cys }\end{array}$ & $42.8 \pm 0.4$ & $12.1 \pm 1.0$ & $\begin{array}{c}-4.5 \pm 0.7 \\
(-2.3 \pm 1.9) \\
b\end{array}$ & $3.8 \pm 0.1$ & $\begin{array}{c}4.1 \pm 0.6 \\
(-1.9 \pm 1.5)^{b}\end{array}$ & $\begin{array}{c}0 \\
(+4.7 \pm 1.7)^{b}\end{array}$ & $1.30 \pm 0.02$ & $\begin{array}{c}21.4 \pm 1.6 \\
(-0.4 \pm 3.1) \\
\mathrm{b}\end{array}$ & $\begin{array}{c}7.8 \pm 1.1 \\
(+3.8 \pm 2.1)^{b}\end{array}$ \\
\hline $\begin{array}{l}\text { F448A } \\
\text { TPL+S-Et- } \\
\text { L-Cys }\end{array}$ & $30.4 \pm 0.5$ & $19.1 \pm 2.0$ & 0 & $2.02 \pm 0.02$ & $-3.2 \pm 0.4$ & $-4.9 \pm 0.9$ & $\mathrm{nd}^{\mathrm{a}}$ & $\mathrm{nd}^{\mathrm{a}}$ & $\mathrm{nd}^{\mathrm{a}}$ \\
\hline
\end{tabular}

${ }^{a}$ nd, not determined.

${ }^{\mathrm{b}} \mathrm{TPL}-\left[{ }^{2} \mathrm{H}\right]-\mathrm{TPL}$

\section{DISCUSSION}

The mechanism of TPL. The mechanism proposed for TPL is shown in Scheme 1. The substrate initially undergoes transaldimination to form an external aldimine, then the $\alpha-\mathrm{C}-\mathrm{H}$ is deprotonated by Lys-257 to give a quinonoid intermediate. Previously, we found that quinonoid complexes can exist in either open or closed conformations, where the small domain rotates toward the large domain to close the active site ${ }^{8,11}$. Elimination of phenol or another leaving group occurs in the 
closed conformation to give a closed aminoacrylate intermediate complex. In addition to TPL, Schiff's base complexes of $\alpha$-aminoacrylate are key intermediates in many PLP-dependent $\beta$-elimination and $\beta$ substitution reactions. Crystal structures of aminoacrylate intermediates of tryptophan synthase ${ }^{27}$, Oacetyl-L-serine sulfhydrylase ${ }^{28}$, cystathionine $\beta$-synthase ${ }^{29}$, alliinase ${ }^{30}$, diaminopropionate ammonia lyase $^{31}$, and O-phosphoserine sulfhydrylase ${ }^{32}$ have been obtained previously. In the present study, we have obtained structures of aminoacrylate complexes of wild-type TPL by soaking the crystals with the native substrate, L-tyrosine, as well as alternative substrates, 3-fluoro-L-tyrosine, S-ethyl-L-cysteine and L-serine, together with 4-PD, a phenol isostere that binds to the aminoacrylate intermediate and stabilizes it ${ }^{12}$. These structures show that quinonoid and aminoacrylate intermediates can exist in both open and closed conformations. We also obtained the structure of an aminoacrylate complex of F448A mutant TPL formed from S-ethyl-L-cysteine and 4-PD. This structure shows that F448A TPL can form an aminoacrylate intermediate in a closed active site. F448A TPL has very low activity (ca. $10^{-4}$ that of wild-type TPL) with L-tyrosine ${ }^{9}$, so we could not obtain an aminoacrylate structure from L-tyrosine or 3-F-L-tyrosine. However, crystals of F448A TPL form a quinonoid complex with 3-F-L-tyrosine ${ }^{11}$.

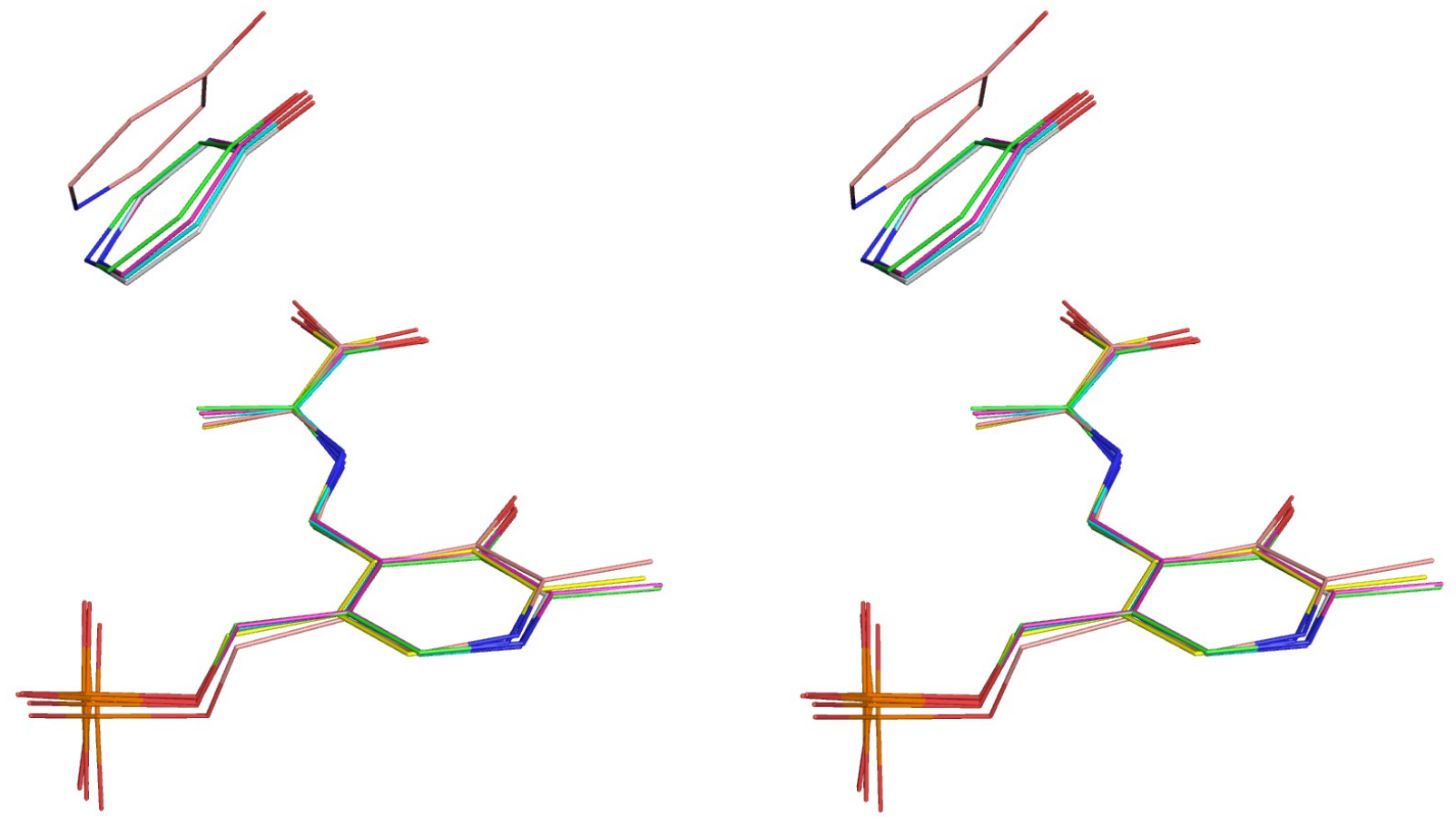

Figure 7. crossed-eye stereo view of the overlay of superposed aminoacrylate (below) and 4-PD (above) structures of TPL. Green: Wild-type TPL from L-tyrosine. Cyan: Wild-type TPL from S- 
ethyl-L-cysteine. Red: Wild-type TPL from L-serine. Yellow: Perdeuterated TPL from S-ethyl-Lcysteine. Gray: Wild-type TPL from 3-F-L-tyrosine. Orange: F448A TPL from S-ethyl-L-cysteine.

The structures of all of the aminoacrylate structures in Figure 7 are identical, within experimental error, regardless of the substrate or form of TPL from which they were formed. It is interesting that they are not completely planar, as might be expected to optimize orbital overlap and maximize $\pi$-system conjugation, but rather there is rotation of the plane of the $\mathrm{C}^{\prime}$ '- $\mathrm{N} \alpha$ imine bond by about $-15^{\circ}$ from the pyridine ring plane (for example, see Figure 1A). Aminoacrylate structures in other PLP-dependent enzymes also show deviation from planarity with the PLP, but the torsion angles are generally less than those of TPL. This distortion may help to make the imine more electrophilic for subsequent nucleophilic attack by the $\varepsilon$-amino group of Lys-257 to form a gem-diamine. We observed an aminoacrylate complex in the B-chain of perdeuterated TPL that is consistent with an aminoacrylate or dehydroalanine gem-diamine (Figure S4B). This is the expected step immediately before product release for TPL. The 4-PD structures in all of the TPL complexes also are superposable, except for that of F448A TPL, which is shifted away from the aminoacrylate (Figure 7). The distance between the N1 of 4-PD in wild type and F448A complexes is about $1 \AA$, and that of O4 is about $1.3 \AA$. In the other TPL structures, the CZ of the phenyl rings of Phe-448 and 449 is in van der Waals contact, about $2.5 \AA$ from 4-PD (Figure 8). However, in F448A TPL, the CZ of Phe-449 is $3.5 \AA$ from 4-PD. The missing phenyl side chain in F448A TPL thus results in more open space in the closed active site, allowing both Phe-449 and 4-PD to have more flexibility. This is also reflected in the increased B-factor of the bound 4-PD, which is $65 \AA^{3}$ for wild-type TPL and $92 \AA^{3}$ for F448A TPL. As a result of this work and previous studies ${ }^{8,10,11,25}$, crystal structures of every proposed intermediate shown in Scheme 1 have been obtained.

The structures of the quinonoid and aminoacrylate complexes of TPL are shown overlaid in Figure 8. In the closed quinonoid conformation, Phe-448 and Phe-449 move toward the substrate. The substrate phenol ring can adopt two structures, one with the normal geometry, but with clashes with 
Phe-448 and Phe-449, and without hydrogen bonds to Thr-124 and Arg-381, and one which is hydrogen bonded, and bent about $20^{\circ}$ out of plane with the bond to $\mathrm{C}_{\beta}$ to relieve the clashes ${ }^{8}$. The aromatic ring of the phenol product in the aminoacrylate complex has rotated upward about $30^{\circ}$, and the $\mathrm{C}_{\gamma}$ has moved $1.3 \AA$ (Figure 8 ) from the bent quinonoid structure. The $\mathrm{O} 4$ has also moved downward, but the hydrogen bonding distances with Thr-124 and Arg-381 are nearly constant in the quinonoid and aminoacrylate structures. The small movement between these central intermediates makes it unlikely that there is a discrete cyclohexadienone intermediate, as has been proposed previously ${ }^{3-7}$. Thus, the transition state geometry for the elimination must lie between the bent quinonoid (green) and aminoacrylate (magenta) structures in Figure 8 . The distortion of the substrate in the bent quinonoid reduces aromaticity and makes the ring more basic, facilitating proton transfer

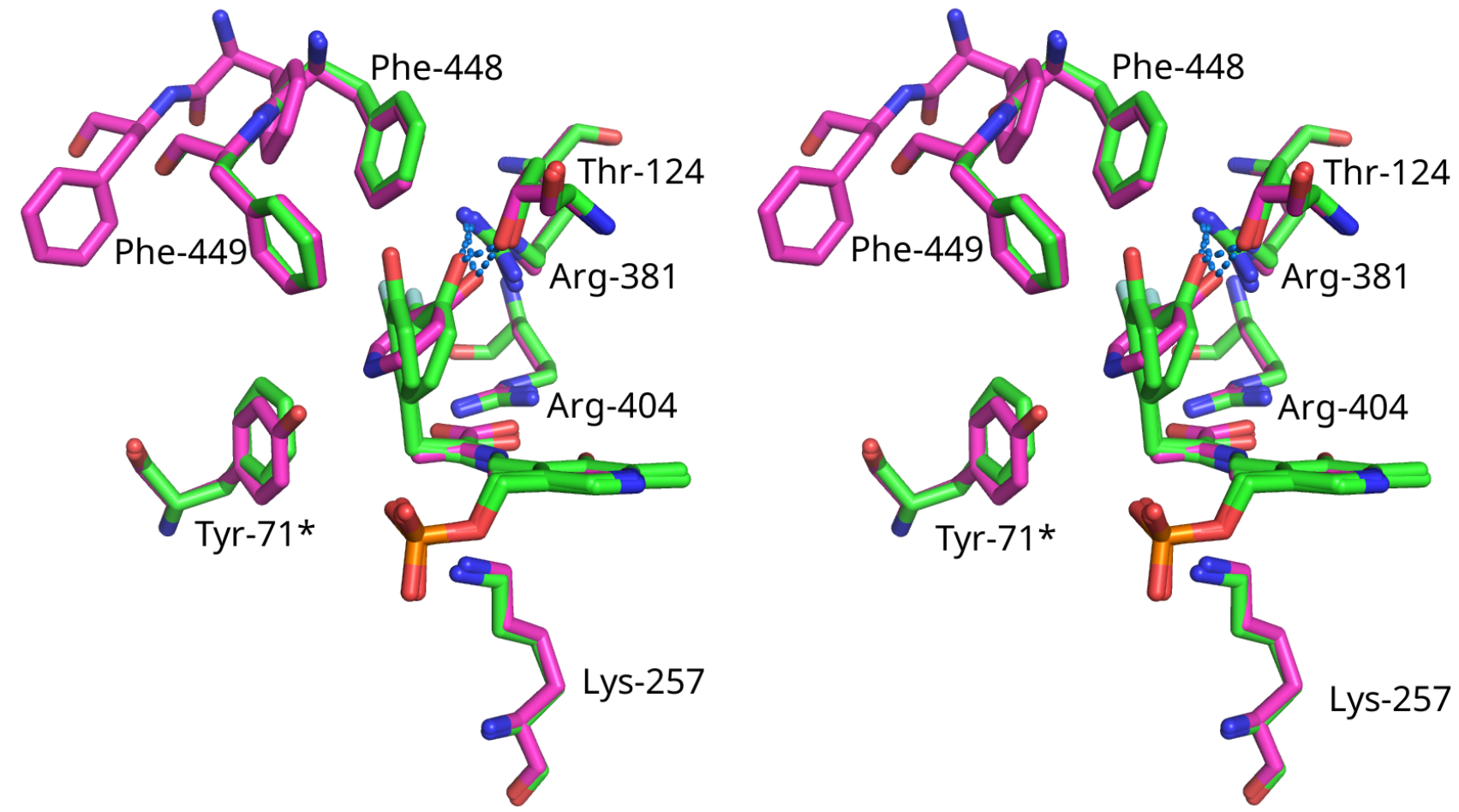

Figure 8. Crossed-eye stereo view of the overlay of the structures of TPL closed quinonoid (2YCN.pdb, green) and aminoacrylate (6MPD.pdb, magenta) complexes of 3-fluoro-L-tyrosine. Hydrogen bonds of the substrate and product with Thr-124 and Arg-381 are indicated by blue dashes.

from Lys-257 through a Grötthuss proton hopping mechanism to Tyr- $71^{*}{ }^{8,11}$, then to $\mathrm{C}_{\gamma}$, most likely concerted with the breakage of the $\mathrm{C}_{\beta}-\mathrm{C}_{\gamma}$ bond to form the phenol product. It should be noted that there 
is a significant KIE on aminoacrylate formation with $\alpha-\left[{ }^{2} \mathrm{H}\right]-\mathrm{L}-$ tyrosine ${ }^{12}$. In the case of F448A TPL, the motion of $\mathrm{C}_{\gamma}$ of the leaving group is at least $2.3 \AA$, and hence the transition state position is much farther from $C_{\beta}$ of the aminoacrylate. This accounts for the low activity $\left(\sim 10^{-4}\right)$ of F448A TPL with Ltyrosine ${ }^{11}$.

Effect of temperature and pressure on TPL intermediate formation. We studied the effect of temperature and hydrostatic pressure on the formation of quinonoid intermediates from S-ethyl-Lcysteine for wild-type, perdeuterated, and F448A TPL (Figures 5A and 6A, $1 / \tau_{1}$ in Tables 1 and 2). Formation of the quinonoid intermediate from wild-type TPL and S-ethyl-L-cysteine has a large positive $\Delta H^{\star}$, but a compensating large positive $\Delta S^{\ddagger}$ reduces $\Delta G^{\ddagger}$. Perdeuteration has only a small effect on quinonoid intermediate formation. With F448A TPL, the rate constant of quinonoid intermediate formation from S-ethyl-L-cysteine is slightly increased, due to a large decrease of $15.8 \mathrm{~kJ} /$ mol in $\Delta H^{\ddagger}$, even though $\Delta S^{\ddagger}$ has become negative. This must be due to the structural changes in the active site resulting from the mutation. The heat capacity, $\Delta C_{\mathrm{p}}^{*}$, is similar and negative for quinonoid intermediate formation from all three enzymes.

The rate of formation of the quinonoid intermediate of S-ethyl-L-cysteine is quite strongly pressure dependent, slowing with increasing pressure for wild-type, perdeuterated and F448A TPL. The activation volume for quinonoid intermediate formation from S-ethyl-L-cysteine by all three enzymes is similar and positive, while the formation of a quinonoid intermediate from 3-F-L-tyrosine by F448H TPL was found previously to have a negative activation volume ${ }^{9}$. This suggests that the transition state for $\mathrm{C}_{\alpha}$-deprotonation is different for these two substrates. This could be due to the formation of new hydrogen bonds in quinonoid intermediates formed by the phenolic group of tyrosine substrates ${ }^{8,11}$. Furthermore, the compressibility, $\Delta \beta^{\ddagger}$, is negative and similar in magnitude for wild-type and perdeuterated TPL, but is eliminated for F448A TPL, consistent with the structural changes in the F448A active site inferred above. 
We studied the effect of temperature on formation of the aminoacrylate intermediate from Ltyrosine and S-ethyl-L-cysteine by wild-type, perdeuterated and F448A TPL (Figure 5). The temperature dependencies of both phases are clearly nonlinear, requiring the use of Equation 5, the macromolecular rate equation ${ }^{21}$, to obtain reasonable fits. For S-ethyl-L-cysteine, $\Delta H^{*}$ is rather large and compensated by a large positive $\Delta S^{\ddagger}$, with a modest negative $\Delta C_{\mathrm{p}}^{\ddagger}$. Although $\Delta H^{\ddagger}$ is reduced in perdeuterated TPL, $\Delta S^{\ddagger}$ is reduced by $19.4 \mathrm{~J} / \mathrm{mol}-\mathrm{K}$ and $\Delta C_{\mathrm{p}}^{*}$ is more negative by $1 \mathrm{~kJ} / \mathrm{mol}-\mathrm{K}$. F448A TPL shows a similar value of $\Delta H^{\ddagger}$, but smaller values of $\Delta C_{\mathrm{p}}^{\ddagger}, \Delta \beta^{\ddagger}$, and $\Delta S^{\ddagger}$, and a negative $\Delta V^{\ddagger}$. In contrast, aminoacrylate formation from L-tyrosine has much lower values of $\Delta H^{\ddagger}$, but large negative values of $\Delta S^{\ddagger}(-100$ to $-200 \mathrm{~J} / \mathrm{mol}-\mathrm{K})$ In particular, the temperature dependent data of the second phase of aminoacrylate formation from L-tyrosine are strongly concave, with a resulting large negative $\Delta \mathrm{C}_{\mathrm{p}}{ }^{*}$ of $-4.8 \mathrm{~kJ} / \mathrm{mol}-\mathrm{K}$ (Figure $5 \mathrm{C}$ ). Negative heat capacities have been seen previously for the reactions of a number of enzymes ${ }^{21,33-38}$. This has been proposed to result from the reduction of protein vibrational motions coupled with the transition state. We also found here that the magnitude of $\Delta C_{\mathrm{p}}^{\ddagger}$ and $\Delta S^{\ddagger}$ for the reaction of L-tyrosine with perdeuterated TPL are reduced due to a heavy enzyme KIE. This is consistent with our previously proposed mechanism where the L-tyrosine substrate is strained by steric contact with Phe-448 and Phe-449 in the closed active site ${ }^{8,11}$ if there is vibrational coupling between these residues and the reaction intermediates and/or if closure of the active site to bring Phe-448 and Phe-449 into contact with the substrate/intermediates is partially rate limiting and isotopically sensitive.

The formation of the aminoacrylate intermediate of wild-type TPL with L-tyrosine shows a large negative activation volume and compressibility, with $\Delta V^{*}=-30 \mathrm{~mL} / \mathrm{mol}$ and $\Delta \beta^{\ddagger}=-36 \mathrm{~mL} / \mathrm{mol}-$ kbar (Figure 6C, Table 2). This large activation volume is unlikely to be the result of motion of the substrate alone, but also suggests that motion of the enzyme, likely the closure of the active site to bring Phe-448 and Phe-449 into contact with the substrate, is necessary for the chemical step. The reaction of perdeuterated TPL with L-tyrosine also has a large negative activation volume and 
compressibility, but which is reduced considerably compared with wild-type TPL (Table 2). The magnitude of the resulting isotope effect is large and may arise due to the involvement of many residues in the relatively large motion of the active site closure, from faster coupling of individual active site residues to the reaction coordinate. The large negative values of $\Delta V^{\ddagger}, \Delta \beta^{\ddagger}, \Delta C_{\mathrm{p}}^{\ddagger}$ and $\Delta S^{\ddagger}$ for aminoacrylate formation with L-tyrosine, but not for S-ethyl-L-cysteine, suggest that the transition state for elimination of phenol from L-tyrosine is highly ordered and stiff, with significant loss of rotational and vibrational freedom of the enzyme and substrate (consistent with the previous observation of a strained L-tyrosine substrate ${ }^{8,11}$, while that for S-ethyl-L-cysteine is much less ordered and stiff.

Heavy enzyme kinetic isotope effects. There are temperature and pressure dependent heavy enzyme deuterium KIEs on formation of quinonoid and aminoacrylate intermediates by TPL (Figure $5 \mathrm{~B}, 5 \mathrm{D}, 5 \mathrm{~F}, 6 \mathrm{~B}$, and $6 \mathrm{D})$. There is a small normal heavy enzyme deuterium KIE on the formation of the quinonoid intermediate of S-ethyl-L-cysteine by perdeuterated TPL which decreases with temperature (Figure 5B), but increases gradually as pressure is increased (Figure 6B). The magnitude of the heavy enzyme deuterium KIE on substrate deprotonation that we see here, ${ }^{\mathrm{H}} \mathrm{k} /{ }^{\mathrm{D}} \mathrm{k}=1.2$ at $1 \mathrm{~atm}$ and $293 \mathrm{~K}$, is similar to that seen with alanine racemase ${ }^{28}$, where the KIE $=1.32$ and 1.21 for the L->D direction and the $\mathrm{D}->\mathrm{L}$ direction, respectively. For alanine racemase, it was concluded that the heavy enzyme kinetic isotope effect is the result of coupling of enzyme vibrational motion with the substrate deprotonation ${ }^{39}$. In contrast with the KIE on quinonoid formation, formation of the aminoacrylate intermediate from S-ethyl-L-cysteine shows a normal KIE that increases with temperature (Figure 5D), but decreases with pressure (Figure 6D). The reaction of unlabeled and perdeuterated TPL with Ltyrosine also shows a strong concave bell shaped dependence on both temperature and pressure (Figure 5E and 6D), becoming inverse at higher temperatures and pressures. These heavy enzyme KIEs intrinsically arise from isotopic differences on $\Delta H^{\ddagger}, \Delta S^{\ddagger}$, and $\Delta V^{\ddagger}$. However, these parameters would lead to simple linear dependencies of heavy enzyme KIEs on temperature and pressure. The curved 
temperature dependences of the heavy enzyme KIEs seen in Figure 5 and 6 are the result of the effects of isotopic substitution on $\Delta C_{\mathrm{p}}^{*}$ and $\Delta \beta^{\ddagger}$, which changes the curvature of the temperature and pressure dependence of the normal and perdeuterated enzymes. This arises because the values of $\Delta C_{\mathrm{p}}^{\ddagger}$ and $\Delta \beta^{\ddagger}$ result from the collective populations of vibrational modes of the enzyme that differ between the reactant state and transition state. These vibrational modes, which could be single bond stretches or more complex protein 'dynamics' such as active site loop or domain motions, are altered by isotopic substitution. Thus, the interpretation of heavy enzyme KIEs as normal or inverse measured at a single temperature or pressure should be done with care. In the case of TPL, the reversible nature of conversion of the quinonoid intermediate to aminoacrylate intermediate, which appears to be coupled to active site loop closure may contribute to the isotope effects observed on $\Delta C_{\mathrm{p}}^{\ddagger}$ and $\Delta \beta^{\ddagger}$.

There have only been two previous reports of an inverse heavy enzyme KIE, and in only one case was the temperature or pressure dependence determined. We have shown here that heavy enzyme KIEs may be either normal or inverse for the same reaction under different conditions. In purine nucleoside phosphorylase, the enzyme labeled with heavy asparagine showed an inverse isotope effect of 0.78 , which was interpreted as evidence for coupled femtosecond motions of the protein with the transition state of the reaction ${ }^{40}$. In pentaerythritol tetranitrate reductase, the heavy enzyme showed an inverse heavy enzyme KIE for FMN reduction with NADPH, but a normal heavy enzyme KIE with NADPH ${ }^{41}$, suggesting that protein vibrations contribute differently to the NADPH and NADH reactions. $^{41}$

Conclusions. TPL forms aminoacrylate intermediates from a wide range of substrates. These intermediates have identical structures regardless of the amino acid from which they are formed. However, not only the rates of formation, but also the values of thermodynamic activation parameters, $\Delta H^{\ddagger}, \Delta S^{\ddagger}, \Delta C_{\mathrm{p}}^{*}, \Delta V^{\star}, \Delta \beta^{\ddagger}$, and heavy enzyme KIEs are different for aminoacrylate intermediate formation from L-tyrosine and S-ethyl-L-cysteine. These results support our proposed mechanism of 
substrate strain in TPL catalysis of the reaction of L-tyrosine, but not S-ethyl-L-cysteine. The negative values of $\Delta C_{\mathrm{p}}^{\ddagger}, \Delta S^{\ddagger}, \Delta V^{\star}$ and $\Delta \beta^{*}$ for L-tyrosine suggest that protein dynamics play an important role in the mechanism of $\beta$-elimination reactions catalyzed by TPL. The crystallographic results demonstrate that conformational dynamics play a key role in aminoacrylate intermediate formation. In contrast to other studies employing heavy enzyme isotope effects where the focus has typically been on fast ps-fs dynamics, we interpret the effect of perdeuteration on the TPL reaction with L-tyrosine as arising through perturbation of necessarily slower protein motions/dynamics involving active site closure, in addition to any effects on vibrational coupling in the transition state. The very different heavy enzyme KIEs observed on the reaction of TPL with L-tyrosine vs. S-ethyl-L-cysteine demonstrates the sensitivity of this analysis and can be rationalized, with the aid of X-ray crystallography, to reflect differences in the (potentially much faster) dynamical coupling of the protein to these substrates. Recently, negative values of $\Delta C_{\mathrm{p}}^{*}$ have been proposed to identify coupling of femtosecond protein vibrational modes to enzyme transition states ${ }^{21,33-38}$. Our results suggest that negative values of $\Delta \beta^{*}$ should be considered as an alternative parameter to determine coupling of protein vibrational modes with enzymatic transition states.

\section{ASSOCIATED CONTENT}

\section{AUTHOR INFORMATION}

\section{Corresponding Author}

Address correspondence to Robert S. Phillips, Department of Chemistry, University of Georgia, Athens, GA 30602

\section{Present Addresses}

\section{Author Contributions}

RSP wrote the paper, determined the crystal structures, and performed the temperature dependent kinetics. SC purified the enzyme and made the crystals. AK, OG and KW prepared the deuterated enzyme and made crystals. AII, DJH and SH performed and analyzed the pressure dependent kinetics. 


\section{Notes}

The authors declare no competing financial interests.

\section{Supporting Information}

The Supporting Information is available free of charge on the ACS Publications website.

The file (Supporting_Information.pdf) contains the statistics for the crystal structures, the mass spectrum of the perdeuterated enzyme, details of the structures of the ligands in the active sites, and the temperature and pressure dependent kinetic data.

\section{ACKNOWLEDGMENT}

Data were collected at Southeast Regional Collaborative Access Team (SER-CAT) 22-ID and 22-BM beamlines at the Advanced Photon Source, Argonne National Laboratory, and the University of Georgia X-ray diffraction Core Facility (XRDC). SER-CAT is supported by its member institutions (see www.ser-cat.org/members.html) and equipment grants (S10 RR25528) and S10 RR028976) from the National Institutes of Health. Use of the Advanced Photon Source was supported by the U. S. Department of Energy, Office of Science, Office of Basic Energy Sciences, under Contract No. W-31109-Eng-3. The XRDC is supported by its UGA member groups (x-ray.uga.edu) and an equipment grant (S10 OD021762) from the National Institutes of Health.

\section{REFERENCES}

1. Kumagai, H.; Yamada, H.; Matsui, H.; Ohkishi, H.; Ogata, K., Tyrosine Phenol Lyase I. Purification, Crystallization, and Properties. J. Biol. Chem. 1970, 245, 1767-1772.

2. Phillips, R. S.; Ravichandran, K.; Von Tersch, R. L., Synthesis of L-Tyrosine From Phenol and S-(ONitrophenyl)-L-Cysteine Catalysed by Tyrosine Phenol-Lyase. Enz. Microb. Tech. 1989, 11, 80-83.

3. Demidkina, T. V.; Barbolina, M. V.; Faleev, N. G.; Sundararaju, B.; Gollnick, P. D.; Phillips, R. S., Threonine-124 and Phenylalanine-448 in Citrobacter freundii Tyrosine Phenol-lyase Are Necessary for Activity with L-Tyrosine. Biochem. J. 2002, 363, 745-752.

4. Kiick, D. M.; Phillips, R. S., Mechanistic Deductions from Kinetic Isotope Effects and pH Studies of Pyridoxal Phosphate Dependent Carbon-Carbon Lyases: Erwinia Herbicola and Citrobacter Freundii Tyrosine Phenol-Lyase. Biochemistry 1988, 27, 7333-7338.

5. Chen, H. Y.; Demidkina, T. V.; Phillips, R. S., Site-Directed Mutagenesis of Tyrosine-71 to Phenylalanine in Citrobacter Freundii Tyrosine Phenol-Lyase: Evidence for Dual Roles of Tyrosine-71 as a General Acid Catalyst in the Reaction Mechanism and in Cofactor Binding. Biochemistry 1995, 34, 12276-12283.

6. Faleev, N. G.; Axenova, O. V.; Demidkina, T. V.; Phillips, R. S., The Role of Acidic Dissociation of Substrate's Phenol Group in the Mechanism of Tyrosine Phenol-lyase. Biochim. Biophys. Acta Prot. Proteom., 2003 1647, 260-265.

7. Faleev, N. G.; Spirina, S. N.; Demidkina, T. V.; Phillips, R. S., Mechanism of Catalysis by Tyrosine Phenol-lyase from Erwinia herbicola. Multiple Kinetic Isotope Effects for the Reactions with Adequate Substrates. J. Chem. Soc., Perkin Trans. 1996, 2, 2001-2004.

8. Milic, D.; Demidkina, T. V.; Faleev, N. G.; Phillips, R. S.; Matkovic-Calogovic, D.; Antson, A. A., Crystallographic Snapshots of Trosine Phenol-lyase Show that Substrate Strain Plays a Role in C-C Bond Cleavage. J. Am. Chem. Soc. (2011)., 133, 16468-16476.

9. Phillips, R. S.; Vita, A.; Spivey, J. B.; Rudloff, A. P.; Driscoll, M. D.; Hay, S., Ground-State Destabilization by Phe-448 and Phe-449 Contributes to Tyrosine Phenol-Lyase Catalysis. ACS Catalysis 2016, 6, 6770-6779. 
10. Milić, D.; Demidkina, T. V.; Faleev, N. G.; Matković-Čalogović, D.; Antson, A. A., Insights into the Catalytic Mechanism of Tyrosine Phenol-lyase from X-ray Structures of Quinonoid Intermediates. J. Biol. Chem. 2008, 283, 29206-29214.

11. Phillips, R. S.; Craig, S., Crystal Structures of Wild-Type and F448A Mutant Citrobacter freundii Tyrosine Phenol-Lyase Complexed with a Substrate and Inhibitors: Implications for the Reaction Mechanism. Biochemistry 2018, 57, 6166-6179.

12. Phillips, R. S.; Chen, H. Y.; Faleev, N. G., Aminoacrylate Intermediates in the Reaction of Citrobacter freundii Tyrosine Phenol-lyase. Biochemistry 2006, 45, 9575-9583.

13. Kabsch, W., XDS. Acta Cryst. 2010, D66, 125-132.

14. Karplus, P. A.; Diederichs, K., Linking Crystallographic Model and Data Quality. Science 2012, 336, 1030-1033.

15. McCoy, A. J.; Grosse-Kunstleve, R. W.; Adams, P. D.; Winn, M. D.; Storoni, L. C.; Read, R. J., Phaser Crystallographic Software. J. Appl. Cryst. 2007, 40, 658-674.

16. Emsley, P.; Cowtan, K., Coot: Model-building Tools for Molecular Graphics. Acta Cryst. D: Biol. Cryst. 2004, 60, 2126-2132.

17. Afonine, P. V.; Grosse-Kunstleve, R. W.; Echols, N.; Headd, J. J.; Moriarty, N. W.; Mustyakimov, M.; Terwilliger, T. C.; Urzhumtsev, A.; Zwart, P. H.; Adams, P. D., Towards Automated Crystallographic Structure Refinement with Phenix.refine. Acta Cryst. D: Biol. Cryst. (2012)., 68, 352367.

18. Laskowski, R. A.; Swindells, M. B., LigPlot+: Multiple Ligand-protein Interaction Diagrams for Drug Discovery. J. Chem. Inf. Model. 2011, 51, 2778-2786.

19. Matheson, I. B. C., The Method of Successive Integration: A General Technique for Recasting Kinetic Equations in a Readily Soluble Form Which Is Linear in the Coefficients and Sufficiently Rapid for Real Time Instrumental Use. Anal. Inst. 1987), 16, 345-373 .

20. http://scidavis.sourceforge.net/index.html Apr 62017.

21. Arcus, V. L.; Prentice, E. J.; Hobbs, J. K.; Mulholland, A. J.; Van der Kamp, M. W.; Pudney, C. R.; Parker, E. J.; Schipper, L. A., On the Temperature Dependence of Enzyme-catalyzed Rates. Biochemistry 2016, 55, 1681-1688.

22. Masson, P.; Balny, C., Linear and Non-linear Pressure Dependence of Enzyme Catalytic Parameters. Biochim. Biophys. Acta .Gen. Sub. 2005, 1724, 440-450.

23. Drewe Jr, W. F.; Dunn, M. F., Characterization of the Reaction of L-Serine and Indole with Escherichia coli Tryptophan Synthase via Rapid-scanning Ultraviolet-visible Spectroscopy. Biochemistry 1986, 25, 2494-2501.

24. Barbolina, M. V.; Phillips, R. S.; Gollnick, P. D.; Faleev, N. G.; Demidkina, T. V., Citrobacter freundii Tyrosine Phenol-lyase: The Role of Asparagine 185 in Modulating Enzyme Function Through Stabilization of a Quinonoid Intermediate. Prot. Eng. 2000, 13, 207-215.

25. https://bib.irb.hr/datoteka/472684.Dalibor_Milic_Doctoral_Thesis.pdf. 2010.

26. Muro, T.; Nakatani, H.; Hiromi, K.; Kumagai, H.; Yamada, H., Elementary Processes in the Interaction of Tyrosine Phenol Lyase with Inhibitors and Substrate. J. Biochem.(Tokyo) 1978, 84, 633640.

27. Ngo, H.; Kimmich, N.; Harris, R.; Niks, D.; Blumenstein, L.; Kulik, V.; Barends, T. R.; Schlichting, I.; Dunn, M. F.,) Allosteric Regulation of Substrate Channeling in Tryptophan Synthase: Modulation of the 1-Serine Reaction in Stage I of the $\beta$-Reaction by $\alpha$-Site Ligands. Biochemistry 2007, 46, 77407753.

28. Schnell, R.; Oehlmann, W.; Singh, M.; Schneider, G., Structural Insights into Catalysis and Inhibition of O-Acetylserine Sulfhydrylase from Mycobacterium Tuberculosis Crystal Structures of the Enzyme $\alpha$-Aminoacrylate Intermediate and an Enzyme-Inhibitor Complex. J. Biol. Chem. 2007, 282, 23473-23481. 
29. Koutmos, M.; Kabil, O.; Smith, J. L.; Banerjee, R.,. Structural Basis for Substrate Activation and Regulation by Cystathionine Beta-synthase (CBS) Domains in Cystathionine $\beta$-synthase. Proc. Natl. Acad. Sci. 2010, 107, 20958-20963.

30. Shimon, L. J.; Rabinkov, A.; Shin, I., Miron, T.; Mirelman, D.; Wilchek, M.; Frolow, F., Two Structures of Alliinase from Alliium sativum L.: Apo Form and Ternary Complex with Aminoacrylate Reaction Intermediate Covalently Bound to the PLP Cofactor. J. Mol. Biol. 2007, 366, 611-625.

31. Bisht, S.; Rajaram, V.; Bharath, S. R.; Kalyani, J. N.; Khan, F.;Rao, A. N.; Savithri, H. S.; Murthy, M. R., Crystal Structure of Escherichia coli Diaminopropionate Ammonia-lyase Reveals Mechanism of Enzyme Activation and Catalysis. J. Biol. Chem. 2012, 287, 20369-20381.

32. Takeda, E.; Kunimoto, K.; Kawai, Y.; Kataoka, M.; Ishikawa, K.; Nakamura, T.,. Role of F225 in O-Phosphoserine Sulfhydrylase from Aeropyrum pernix K1. Extremophiles (2016), 20, 733-745.

33. Arcus, V. L.; Pudney, C. R., Change in Heat Capacity Accurately Predicts Vibrational Coupling in Enzyme Catalyzed Reactions. FEBS Letts. 2015, 589, 2200-2206.

34. Arcus, V. L.; Prentice, E. J.; Hobbs, J. K.; Mulholland, A. J.; Van der Kamp, M. W.; Pudney, C. R.; Parker, E. J.; Schipper, L. A., On the Temperature Dependence of Enzyme-catalyzed Rates. Biochemistry 2016, 55, 1681-1688.

35. Van der Kamp, M. W.; Prentice, E. J.; Kraakman, K. L.; Connolly, M.; Mulholland, A. J.; Arcus, V. L., Dynamical Origins of Heat Capacity Changes in Enzyme-catalysed Reactions. Nature Comm. 2018, 9, 1177.

36. Firestone, R. S.; Cameron, S. A.; Karp, J. M.; Arcus, V. L.; Schramm, V. L., Heat Capacity Changes for Transition-state Analogue Binding and Catalysis with Human 5'-Methylthioadenosine Phosphorylase. ACS Chem. Biol. 2016, 12, 464-473.

37. Jones, H. B.; Wells, S. A.; Prentice, E. J.; Kwok, A.; Liang, L. L.; Arcus, V. L.; Pudney, C. R., A Complete Thermodynamic Analysis of Enzyme Turnover Links the Free Energy Landscape to Enzyme Catalysis. FEBS J. 2017, 284, 2829-2842.

38. Jones, H. B.; Crean, R. M.; Matthews, C.; Troya, A. B.; Danson, M. J.; Bull, S. D.; Arcus, V. L.; Van Der Kamp, M. W.; Pudney, C. R., Uncovering the Relationship Between the Change in Heat Capacity for Enzyme Catalysis and Vibrational Frequency Through Isotope Effect Studies. ACS Catalysis 2018, 8, 5340-5349.

39. Toney, M. D.; Castro, J. N.; Addington, T. A., Heavy-enzyme Kinetic Isotope Effects on Proton Transfer in Alanine Racemase. J. Am. Chem. Soc. 2013, 135, 2509-2511.

40. Harijan, R. K.; Zoi, I.; Antoniou, D.; Schwartz, S. D.; Schramm, V. L., Inverse Enzyme Isotope Effects in Human Purine Nucleoside Phosphorylase with Heavy Asparagine Labels. Proc. Natl. Acad. Sci. 2018, 115, E6209-E6216.

41. Longbotham, J. E.; Hardman, S. J.; Görlich, S.; Scrutton, N. S.; Hay, S., Untangling Heavy Protein and Cofactor Isotope Effects on Enzyme-catalyzed Hydride Transfer. J. Am. Chem. Soc. 2016, 138, 13693-13699. 
Table of contents graphic

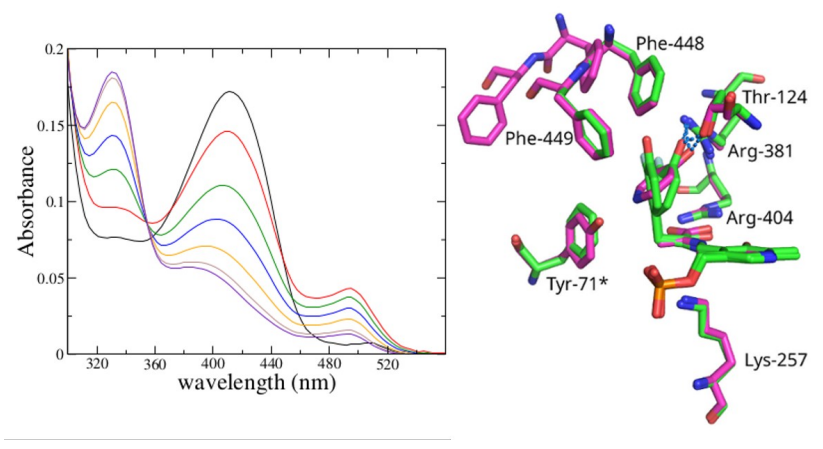

